دراسة تأثير طريقة الرص على الخصائص الهندية لتربة طينية انتفاخية

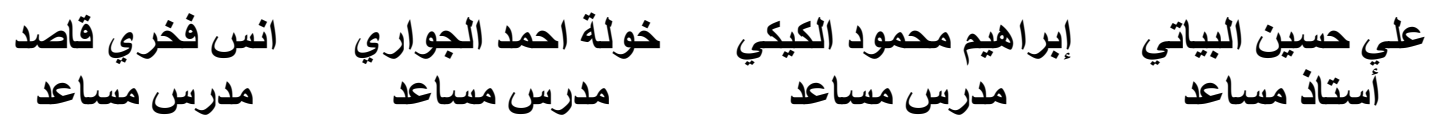
جامعة الموصل- كلية الهندسة

\begin{abstract}
الخلاصة
يتتـاول البحث در اسـة تأثير طريقتي الرص (السـاكن و الديناميكي) على صـائص الهندسية لتربة طينية عالية اللدونة (CH) مختارة من مدينة الموصل.

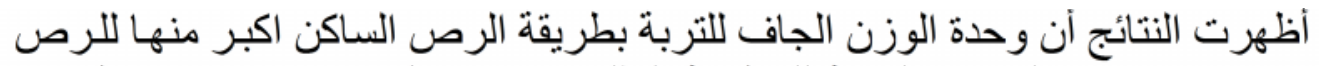

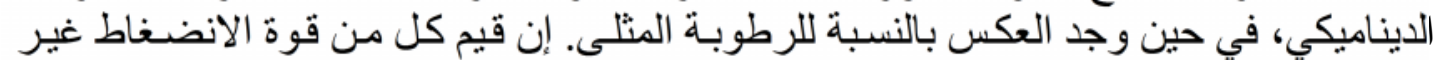

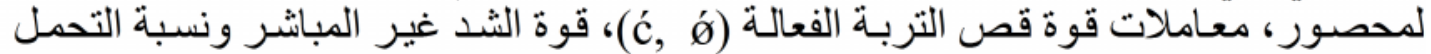

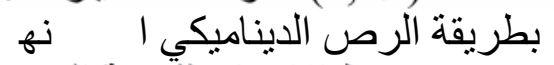

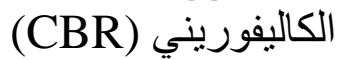

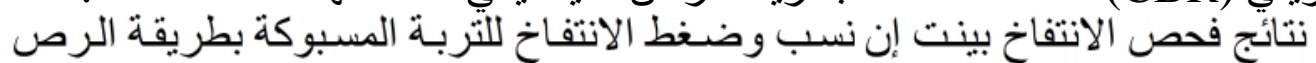

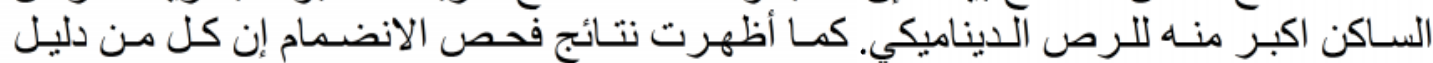

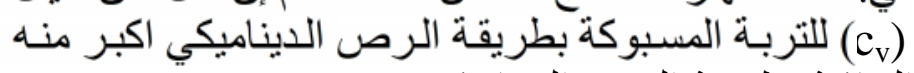

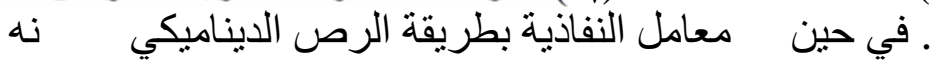

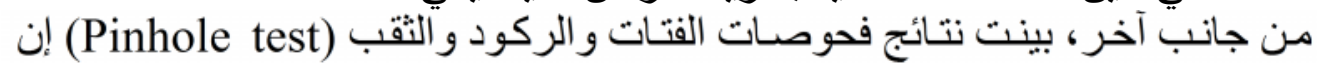

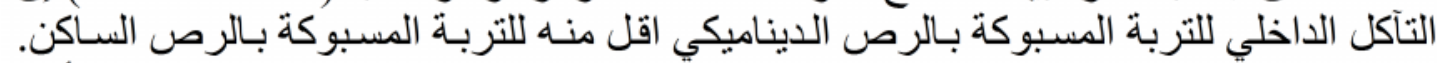

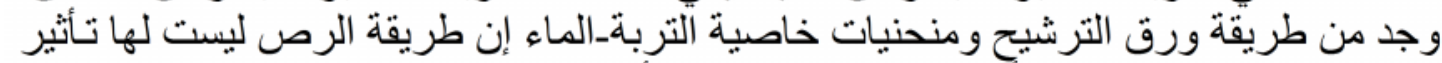

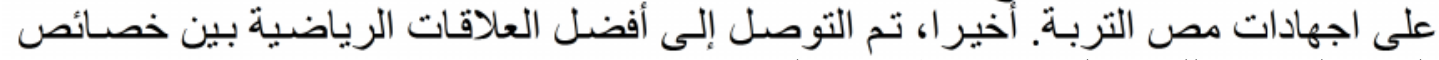

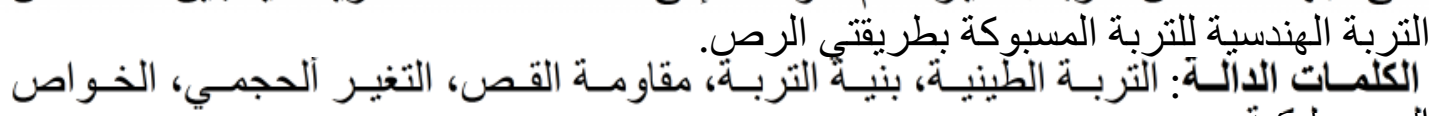

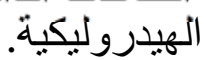

\title{
Studying The Influence Of Compacting Method On The Engineering Properties Of Expansive Clayey Soil
}
Ali H. Al-
Ibrahim M. Al-
Khawla A. Al-
Anas F. Bayati Kiki Juari Qassid

\section{College of Engineering - University of Mosul}

Abstract

This study deals with the effect of two methods of compaction (static compaction (S.C.) and dynamic compaction (D.C.)), on the 
engineering properties of high plasticity clayey soil $(\mathrm{CH})$ selected from Mosul city.

Results showed that maximum dry density of soil compacted by static method is higher than that compacted by dynamic method. But the inverse was obtained for optimum moisture content. Unconfined compressive strength, effective shear strength parameters (ć, Ǿ), splitting and California Bearing Ratio (CBR) for soil compacted by dynamic method has higher values than that compacted by static method.

Swelling pressure and free swell tests gave higher values under static compaction method. But the values of compression index and coefficient of consolidation using dynamic compaction method gave higher values.

On the other hand, the results of crumb, slackening and pinhole tests showed that the internal erosion of soil compacted by dynamic method are less than that compacted by static method. From filter paper method and soil water characteristic curves showed that compaction methods had no effect on soil suction. Finally, statistical models between engineering properties for soil compacting by two methods were obtained.

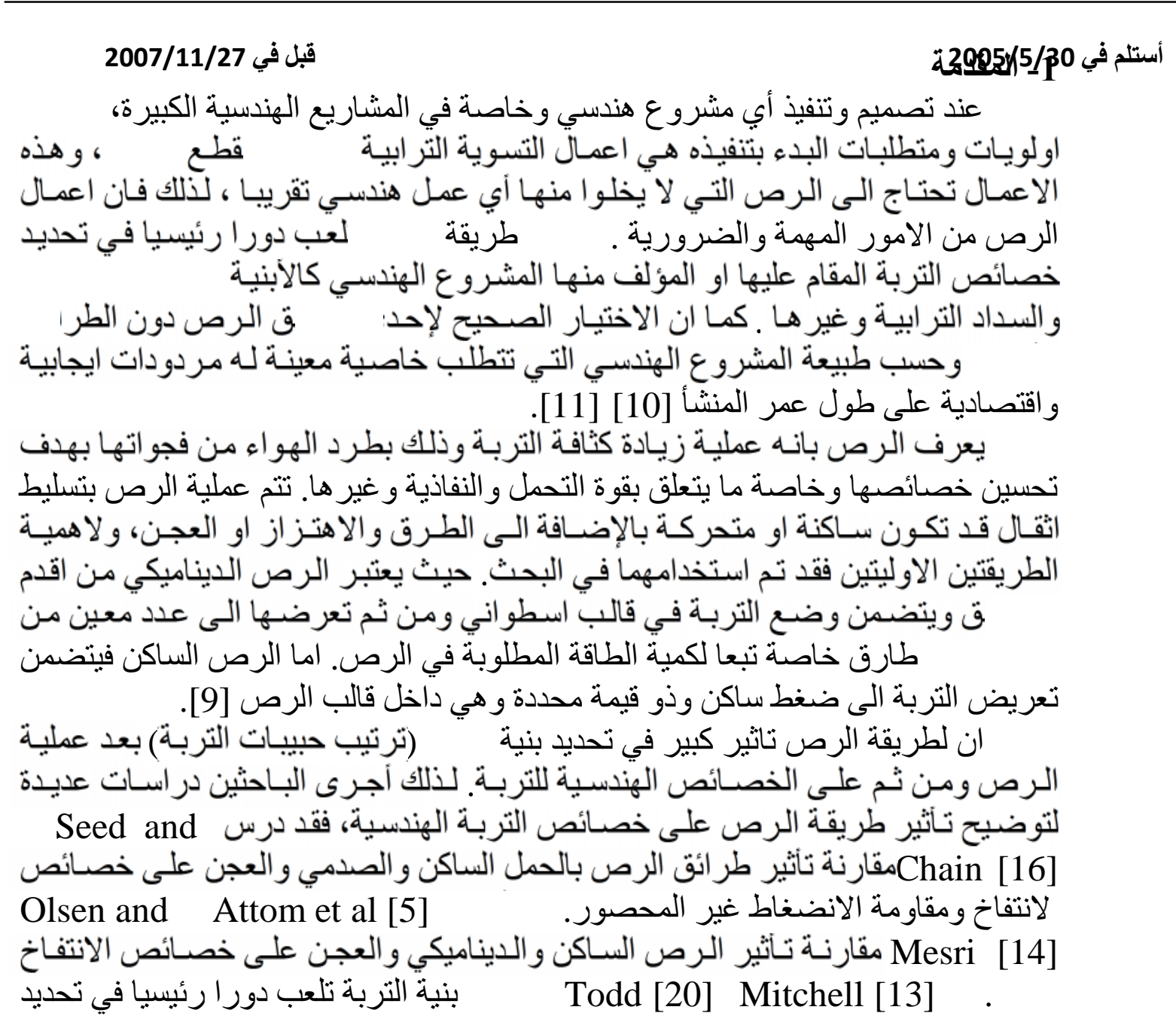


الخصائص الهندسية للتربة الطبيعية او الترب المرصوصة في في الاعمـال الانثـائية وخاصـة

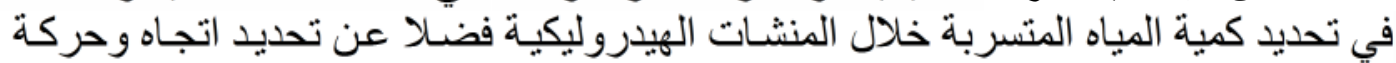

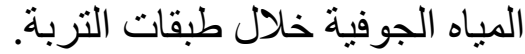

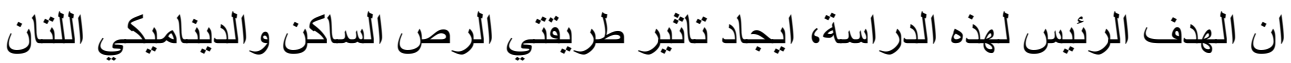

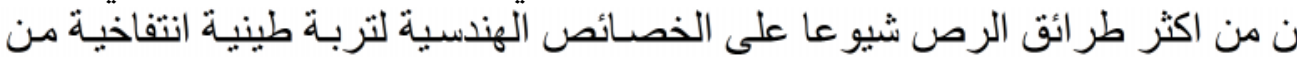

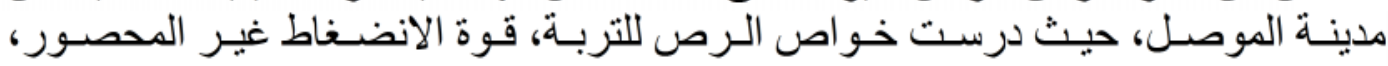

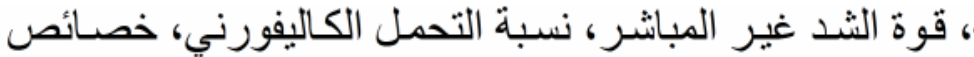

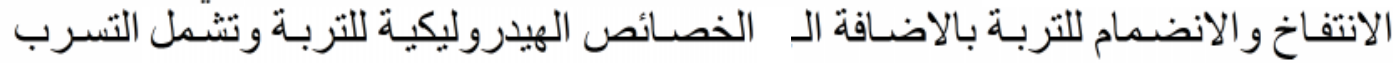
النفاذية.

\section{2 - المواد المستخدمة وطرائق العمل} 1-2 - 2 - 2 المواد المستخدمة:

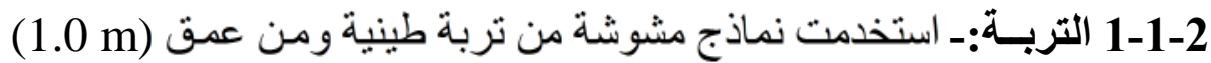

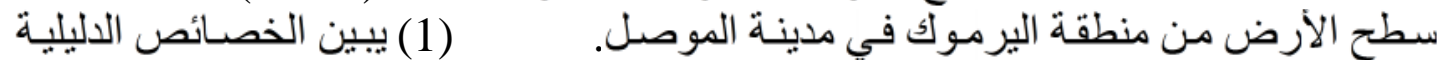

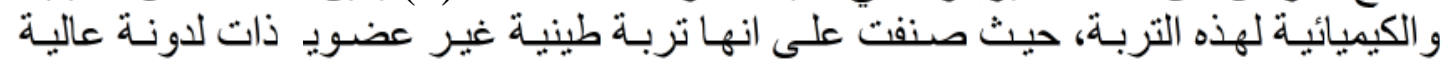

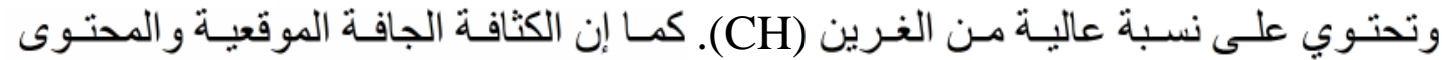

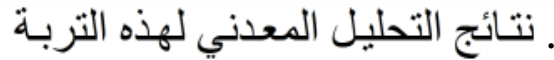

$\left(15 \%, 16.0 \mathrm{kN} / \mathrm{m}^{3}\right)$

مبينة في الثكل (1)، شملت مكونات التربة المعدنية على المعادن الطينية الرئيسة وهي طبقات لهذب التربة

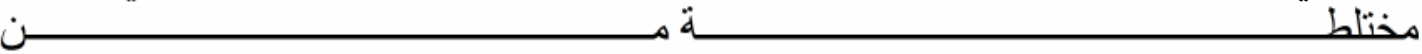

( المونتموريلونايت + الكلور ايت) و الكلور ايت فضـلاً عن الباليكورسكايت، المعادن الطينية

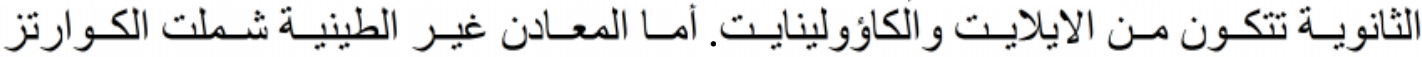
و الكالسايت.

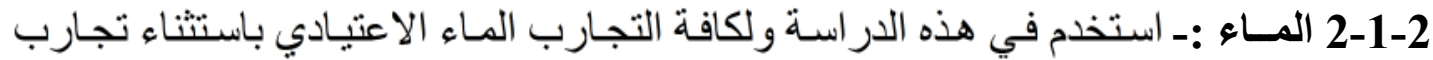
الخصائص الاليلية والفحوصات الكيميائية للتربة فقد استخدم الماء المقطر.

2-2 2 إعداد النماذج للفحص:

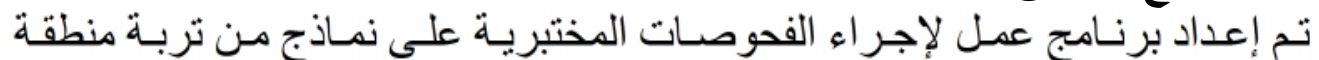

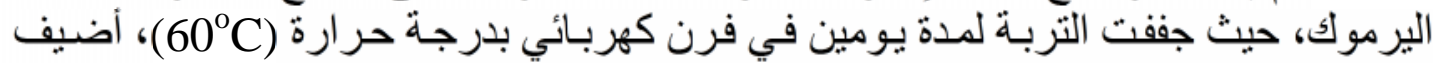

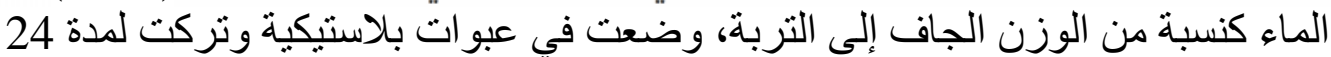

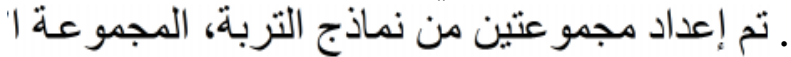

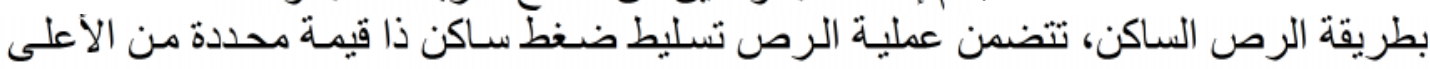
[9]. اما المجموعة الثانية سبكت النماذج بطريقة

الرص الديناميكي وحسب المو اصفة (1557-79 (ASTM D 15). (1 )* الخصائص الدليلية للتربة الطبيعية المستخدمة في البحث

\begin{tabular}{|c|c|c|}
\hline 51 & \% (L.L) حد السيولة| & \\
\hline 24 & \% (P.L) & \\
\hline 27 & \% (P.I) دليل اللدونة (L.S) \\
\hline 14.6 & \% (L.S) \\
\hline
\end{tabular}




\begin{tabular}{|c|c|c|}
\hline 2.72 & \multicolumn{2}{|c|}{ (Gs) } \\
\hline $\mathrm{CH}$ & \multicolumn{2}{|c|}{ حسب نظام التصنيف الموحد ( U.C.S.) } \\
\hline Group $=\mathrm{A}-7$ & & \multirow[t]{2}{*}{ تصني } \\
\hline $\begin{array}{c}\text { Sub } \\
\text { Group=A-7- } \\
6\end{array}$ & $\begin{array}{r}\text { تصنيف الجمعية الأمريكية للطرق } \\
\text { (AASHTO C.S.) }\end{array}$ & \\
\hline 3 & $4.76<\%$ & \multirow{4}{*}{ التحبيل التيبي } \\
\hline 12 & $4.76 \geq \%>0.074$ & \\
\hline 45 & 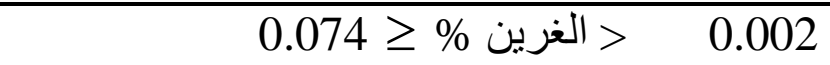 & \\
\hline 40 & الطين \% > 0.002 & \\
\hline 0.71 & \multicolumn{2}{|c|}{ الفعالية (Activity) } \\
\hline 1.3 & $\%$ & \multirow{6}{*}{ الكيميائية } \\
\hline 1.46 & نسبة المو اد العضوية \% & \\
\hline 0.3 & املاح الكبريتات (SO $)$ \%) & \\
\hline 2.25 & الاملاح الذائبة الكلية (T.S.S) & \\
\hline 8.54 & الرقم الهيدروجيني (pH -value) & \\
\hline 28 & 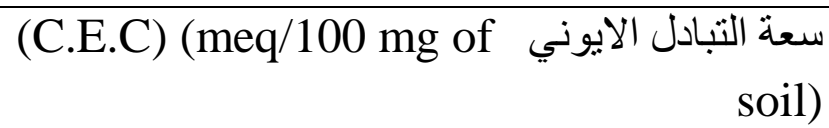 & \\
\hline
\end{tabular}

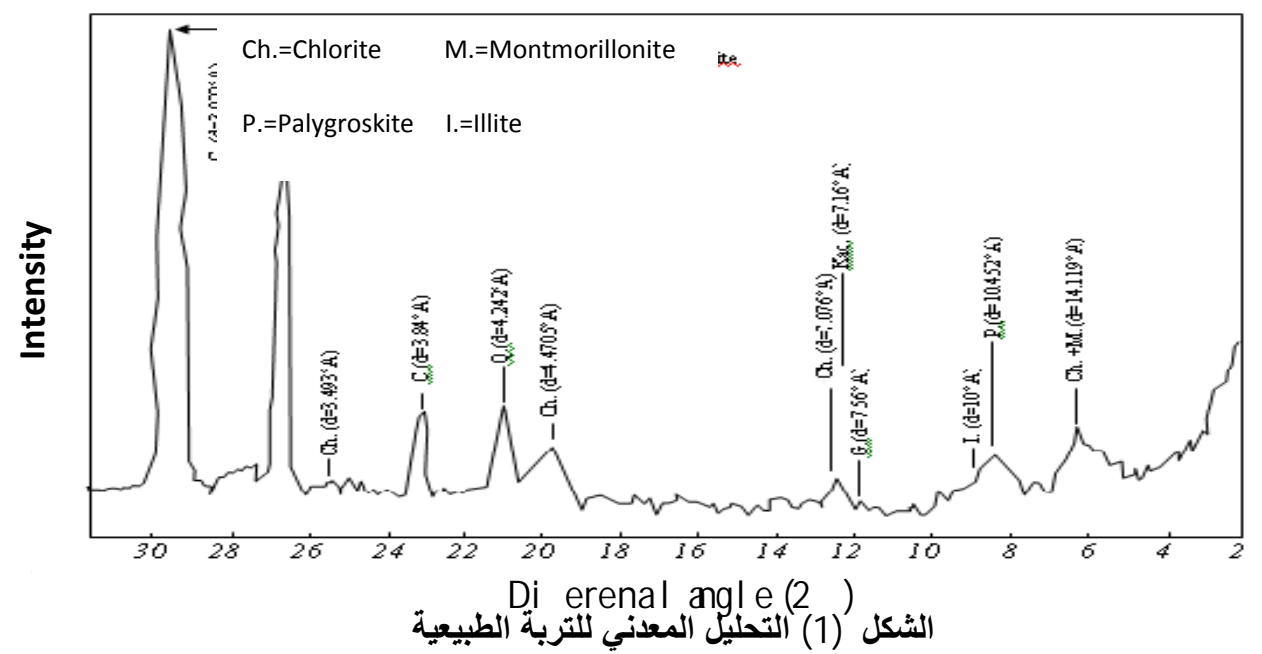


3-2 - 2 - 3حوصات المختبرية:

وصو لاً لهاف البحثث أجريت العديد من الفحوصـات الهندسية، الجدول (2) يبين هذه البها

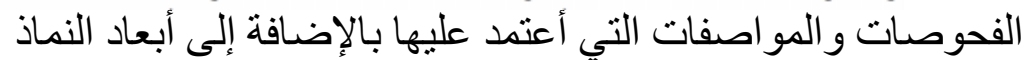

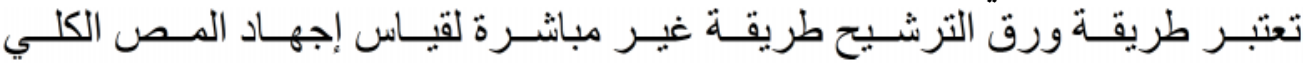

و والمص النسيجي (Total Suction)

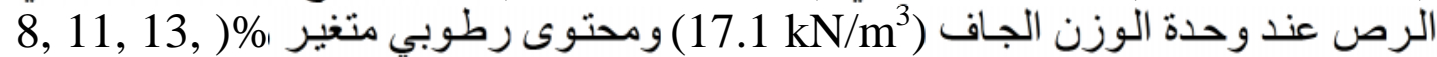

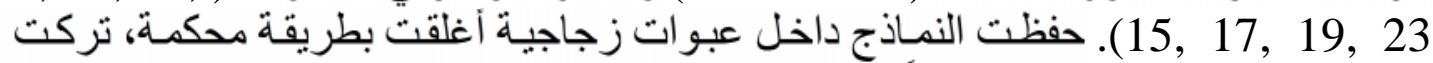

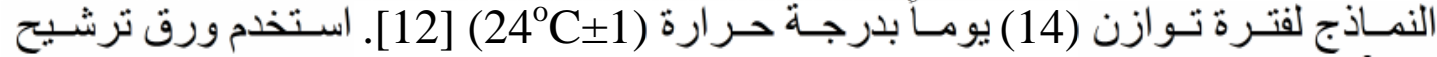
الزمنة $\quad$ S\&S Round Filter No.58933

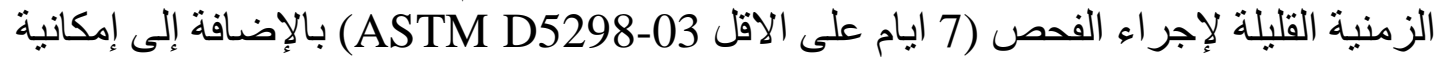

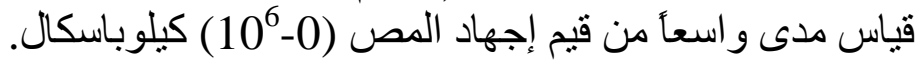

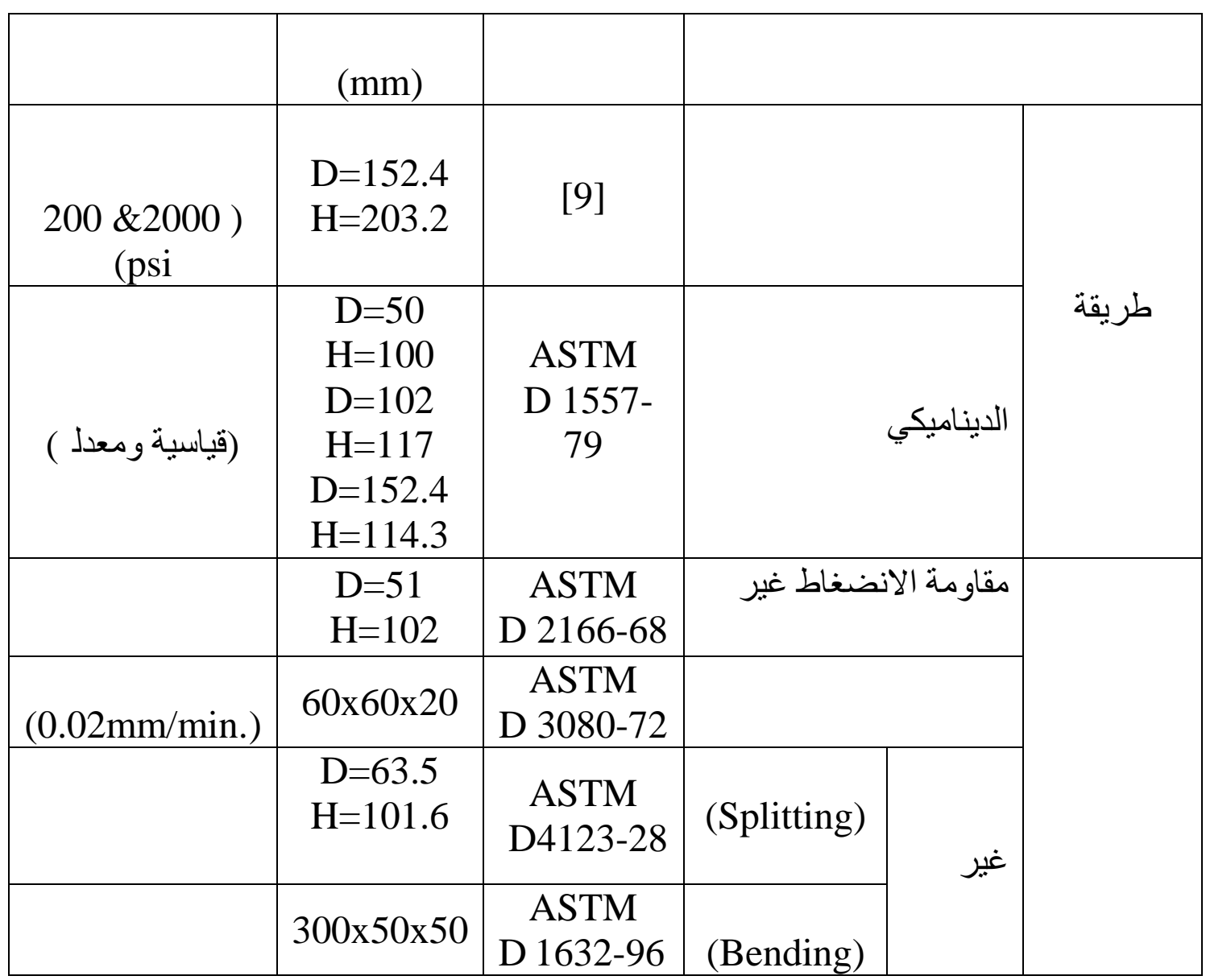




\begin{tabular}{|c|c|c|c|c|c|}
\hline & $\begin{array}{l}\mathrm{D}=152.4 \\
\mathrm{H}=114.3\end{array}$ & $\begin{array}{c}\text { AASHTO } \\
\text { T193-72 }\end{array}$ & \multicolumn{2}{|c|}{$\begin{array}{r}\text { نسبة التحمل الكاليفورني } \\
\text { (CBR) }\end{array}$} & \\
\hline & \multirow{2}{*}{$\begin{array}{c}D=63.5 \\
H=19\end{array}$} & $\begin{array}{c}\text { ASTM } \\
\text { D 2435-80 }\end{array}$ & & & \multirow{2}{*}{ التغير } \\
\hline & & $\begin{array}{c}\text { ASTM } \\
\text { D 4546-91 }\end{array}$ & & & \\
\hline & $\begin{array}{c}\mathrm{D}=51 \\
\mathrm{H}=102\end{array}$ & $\begin{array}{c}\text { ASTM } \\
\text { EM 1110- } \\
2-70 \\
15]\end{array}$ & & & \multirow{5}{*}{ الهيدروليكية } \\
\hline $\begin{array}{l}(4 \mathrm{~mm}) \\
(30 \mathrm{~min} .)\end{array}$ & $\begin{array}{l}D=106 \\
H=117\end{array}$ & $\begin{array}{c}\text { ( WES) } \\
\text { EM 1110- } \\
2-80\end{array}$ & (Pinhole) & & \\
\hline \multirow[t]{3}{*}{ الانضمام ايضـاً } & $\begin{array}{c}D=63.5 \\
H=19\end{array}$ & $\begin{array}{c}\text { Variable } \\
\text { head } \\
\text { method } \\
{[9]}\end{array}$ & \multicolumn{2}{|r|}{ النفاذية } & \\
\hline & $\begin{array}{l}D=63.5 \\
H=25.4\end{array}$ & $\begin{array}{c}\text { ASTM } \\
\text { D 5298-03 }\end{array}$ & ورق الترشيح & \multirow{2}{*}{ اجهادات } & \\
\hline & $\begin{array}{l}\mathrm{D}=30 \\
\mathrm{H}=12\end{array}$ & [8] & & & \\
\hline
\end{tabular}

(2) الفحوصات المختبرية ومو اصفاتها القياسية وابعاد النماذج

3 - النتائج والمناقشة

1-3 تأثير طريقة، طاقة وقطر اسطوانة الرص على خصائص الرص:

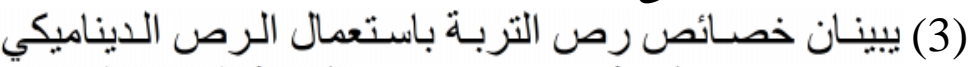

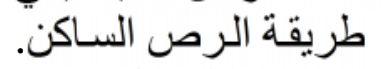

بالطاقة القياسية و المعدلة مع اختلاف حجم الاسطو انة الينة

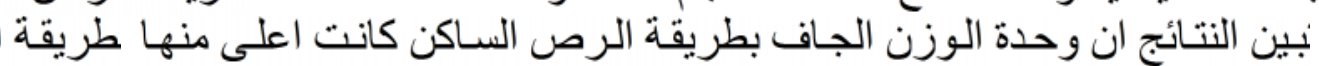

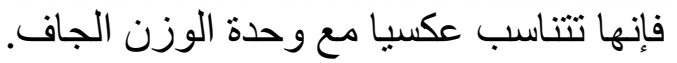

العظمى، حيث تزداد بزيادة الاسطو انة بينمـا

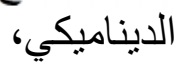

تأثتير محدود 


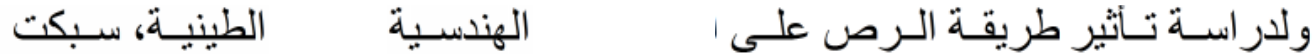

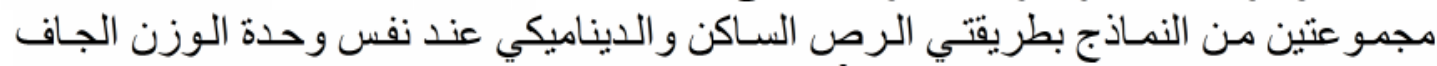
(18\%, 17.1 kN/m² )

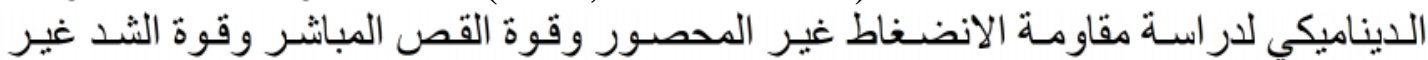

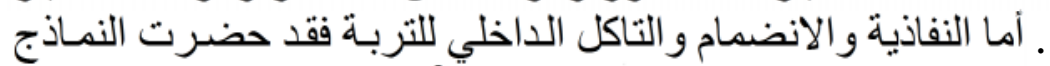

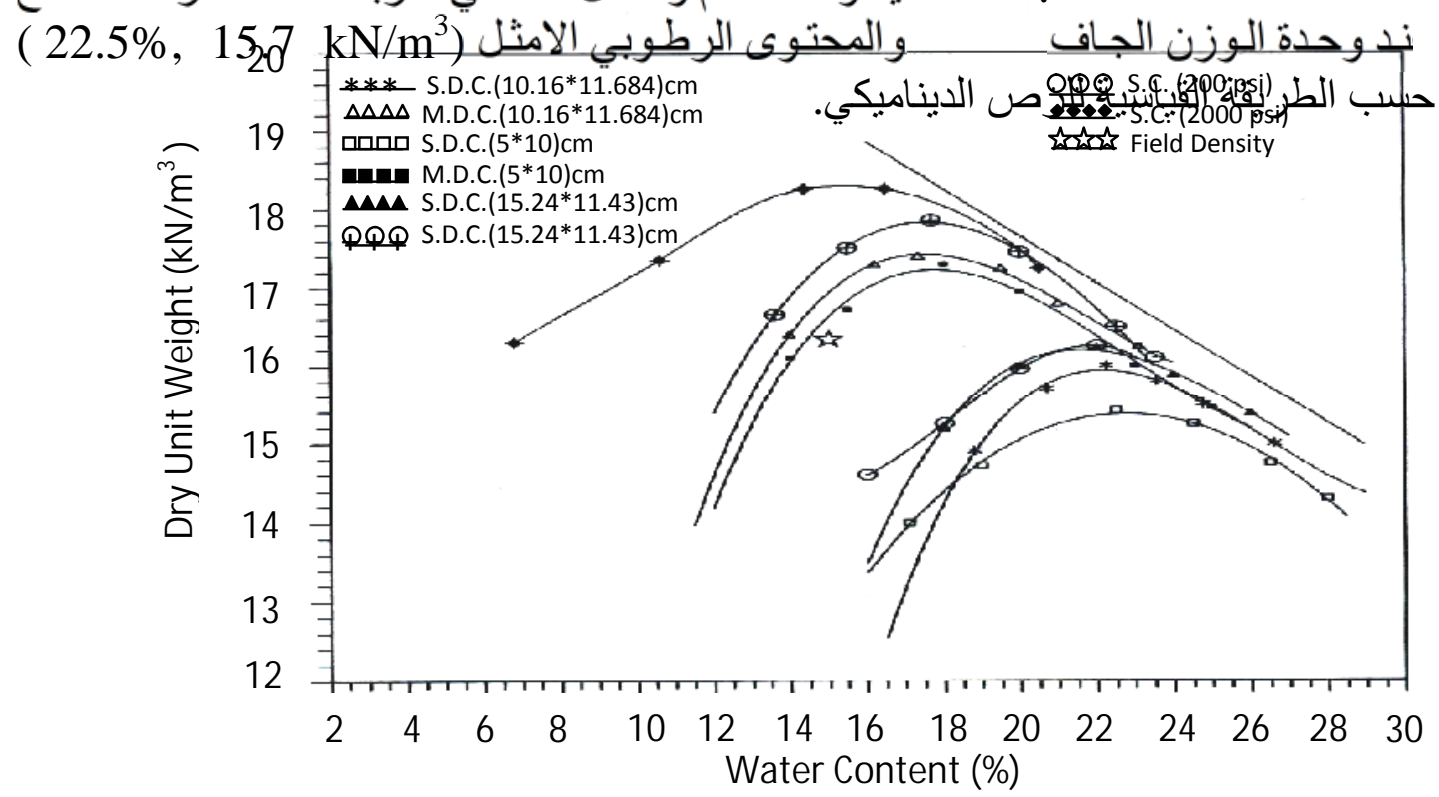

الثكل (2) العلاقة بين المحتوى الرطوبي والكثافة الجافة للتربة الطبيعية ( منحنيات الرص )

(3) نأثير طريقة الرص و ابعاد اسطو انة 


\begin{tabular}{|c|c|c|c|c|}
\hline$\left(\mathrm{kN} / \mathrm{m}^{3}\right)$ & $(\%)$ & & $(\mathrm{mm})$ & طريقة \\
\hline 15.1 & 22.5 & القياسية & \multirow{2}{*}{$50 \times 100$} & \multirow{6}{*}{$\begin{array}{c}\text { الديناميكي } \\
\text { (D.C.) }\end{array}$} \\
\hline 16.9 & 18.0 & & & \\
\hline 15.7 & 22.5 & القياسية & ) & \\
\hline 17.1 & 18.0 & & $102 \times 117$ & \\
\hline 15.9 & 22.5 & القياسية & \multirow{2}{*}{$152.4 \times 114.3$} & \\
\hline 17.5 & 18.0 & & & \\
\hline 16.0 & 21.5 & 200 Psi & \multirow[b]{2}{*}{$152.4 \times 203.2$} & \\
\hline 18.0 & 15.0 & $\begin{array}{c}2000 \\
\text { Psi }\end{array}$ & & (S.C.) \\
\hline
\end{tabular}

2-3 تاثير طريقة الرص على بنية التربة:

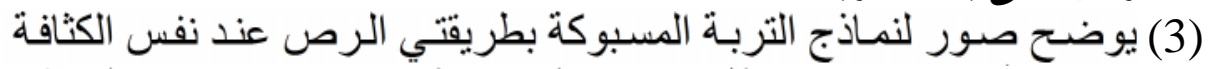

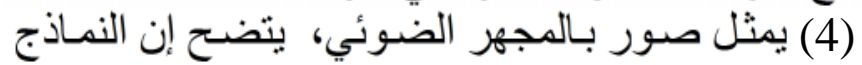

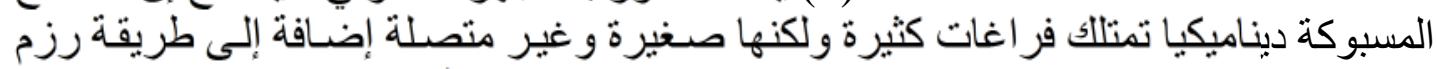

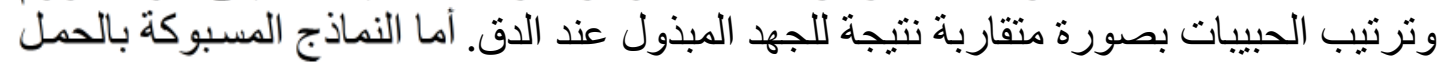

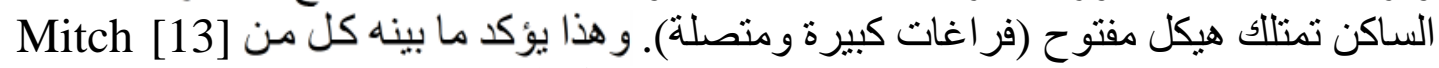
رSeed and chain [16] رصها بطريقة العجن فان بنية التربة تكون منو ازية وكما مبين في الثكل (5).

3-3-3 تأثير طريقة الرص على مقاومة التربة:

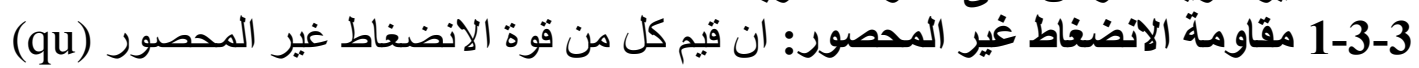

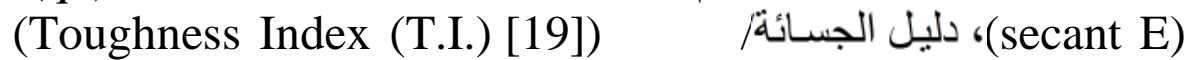
بطريقة الرص الديناميكي

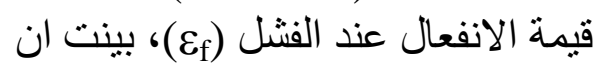

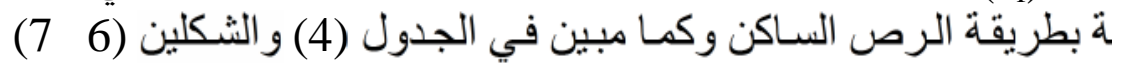

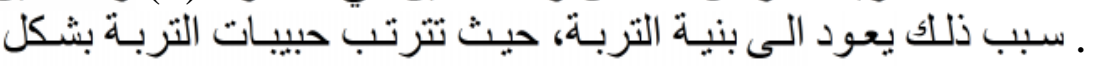

(Dispersed)

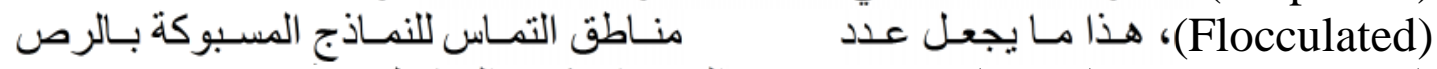

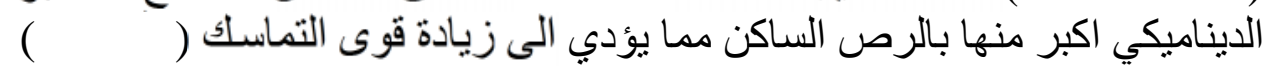

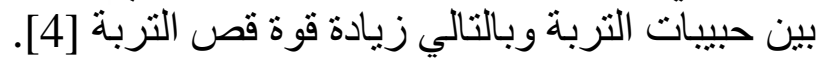


2-3-3 قوة القص المباشر: معاملات قص التربـة الفعالة (زاويـة الاحتكالك الداخلي الفعالة

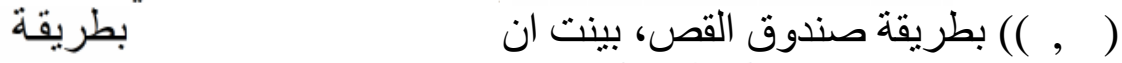

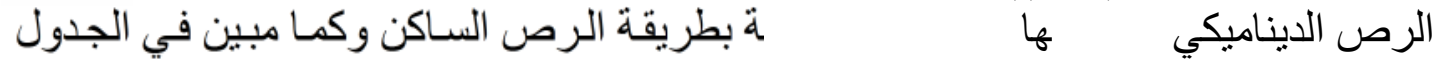

الانشطار بطريقتي الفحص 3-3-3 قوة الثد غير المباشر: بينت

(Bending / Flectural test)

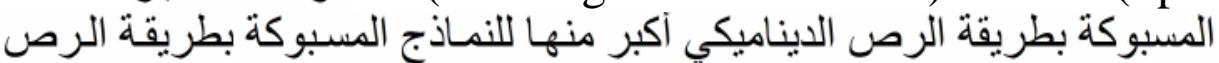

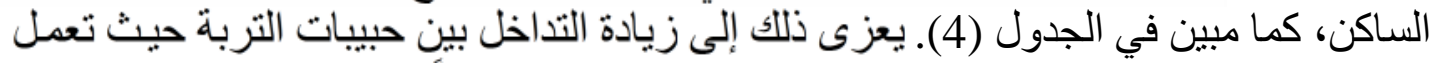

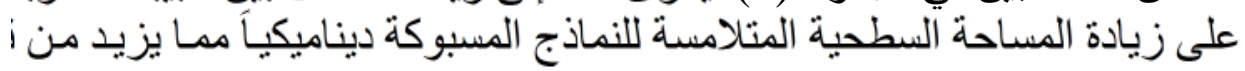
التربة كما مبين في الثكل (4).

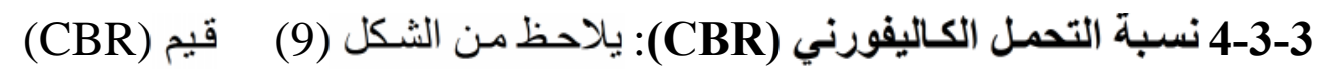

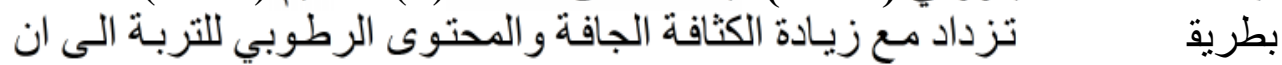

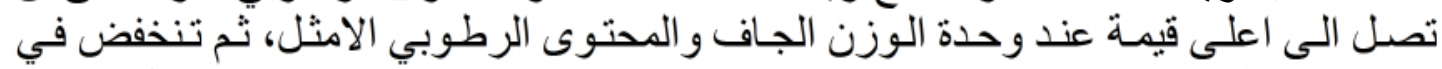

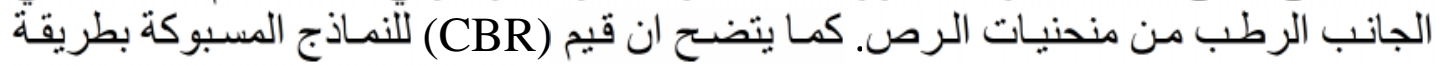

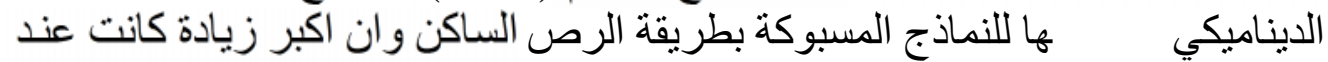

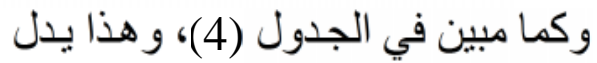

على أن بنية التربة لها تأثير كبير على نسبة التحمل الكاليفورني.

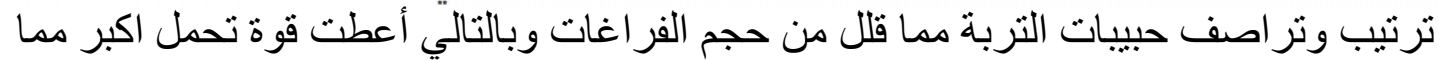

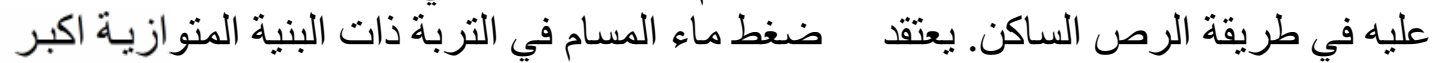
مما هو عليه في التربة ذات البنية المتعامدة [16].

4-3 تأثير طريقة الرص على التفير الحجمي للتربة:

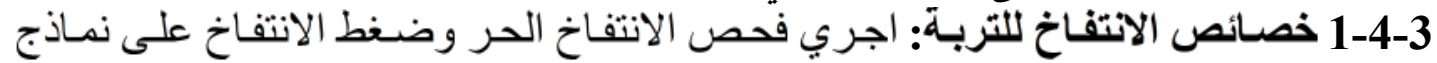
مسبوكة بطريقتي الرص عند الأنداخ وحدة الوزن الجرن الجاف

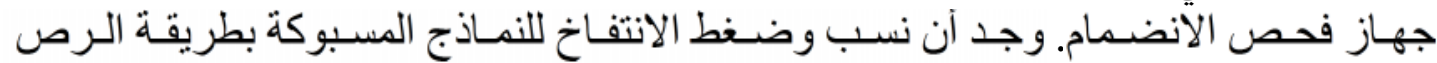

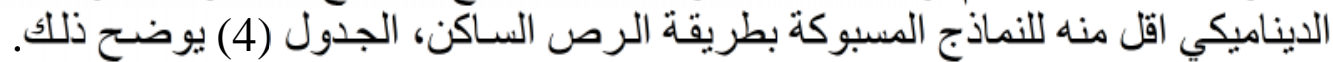
هذه النتائج مع ما توصل اليهـ Seed and Chain [16 عند استخدامه لطر ائق الرص لأرص الساكن (10) يبين أن نسب الانتفاخ تقل عند زيادة المحتوى الرطوبي الابتدائي، كما

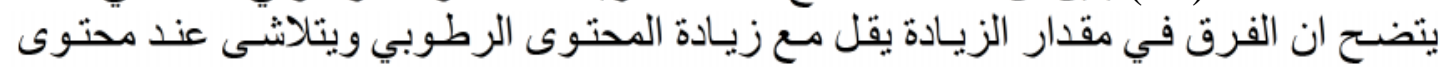
. \%22.7) 


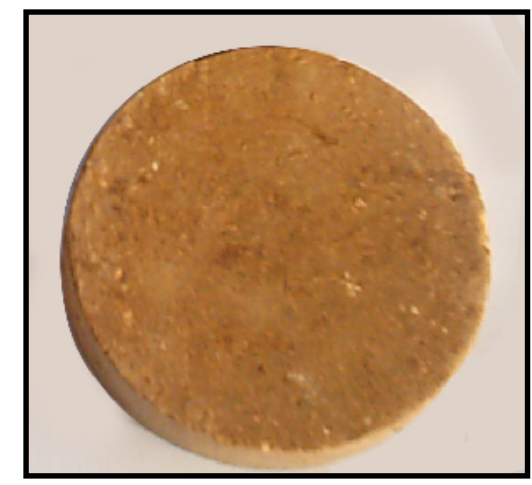

نموذج تربة مسبوك ديناميكيا (b)

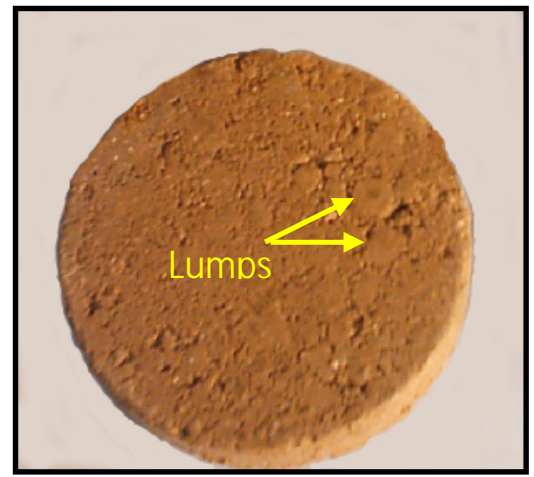

نموذج تربة مسبوك استاتيكيا

(3)

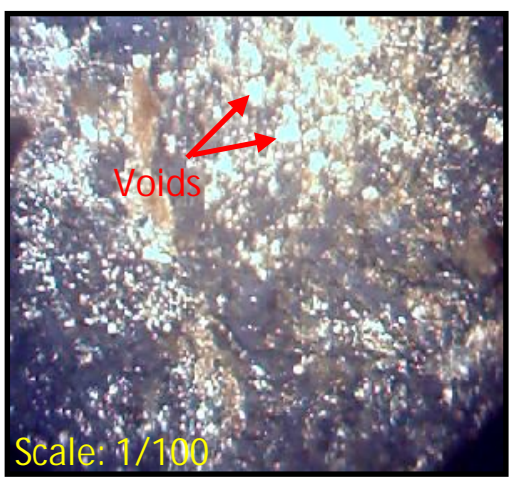

نموذج تربة مسبوك ديناميكيا (b)

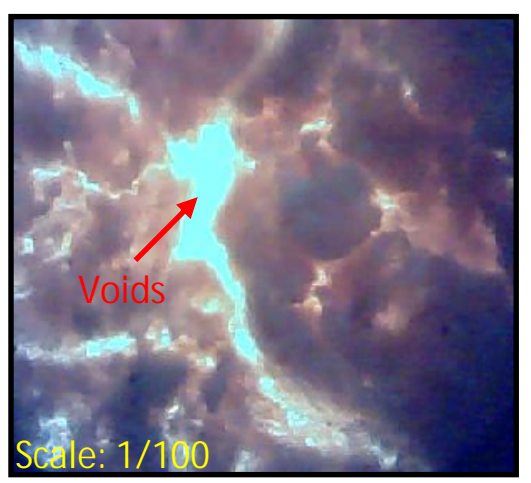

(a) نموذج تربة مسبوك استاتيكيا

(4) صور بالمجهر ا

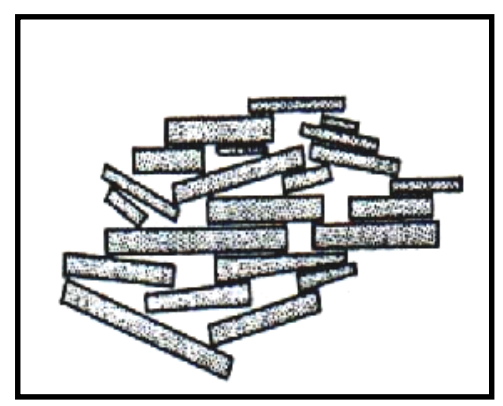

Dispersion Soil التربة المشتتة (b)

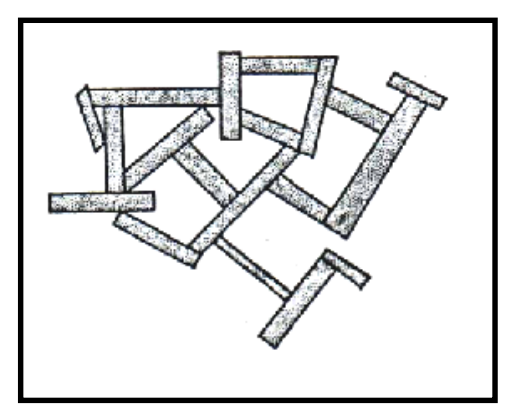

Flocculation Soil التربة المتلبدة (a) 
(5) بنية التربة [6] 
(4) نأثثر طريقة الرص على الخصائص الهندية للتربة الطينية

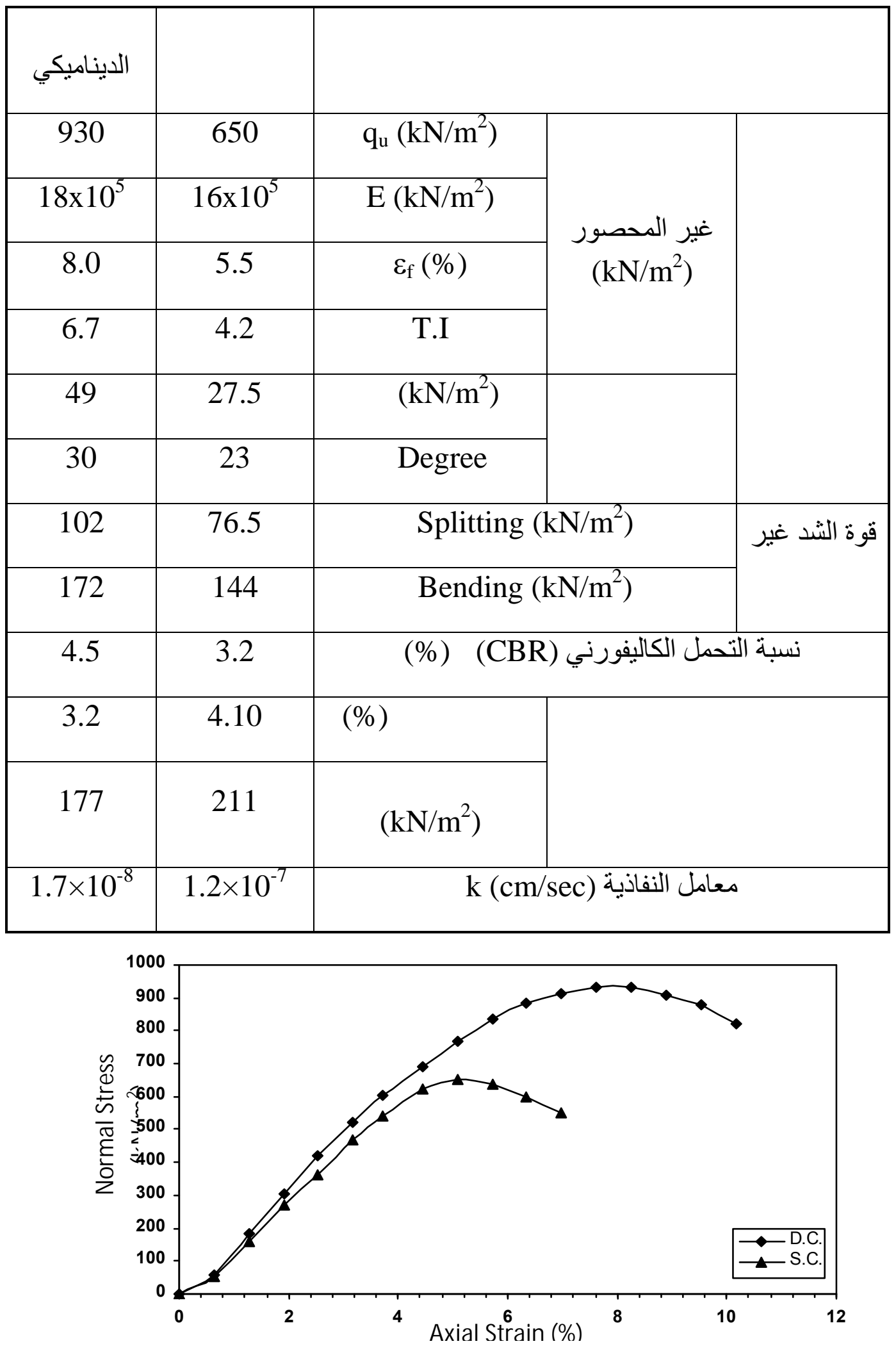


(6) ناثير طريقة الرص على العلاقة بين الاجهاد و الانفعال لـ

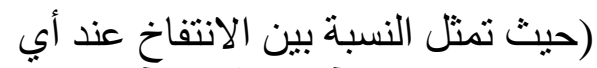

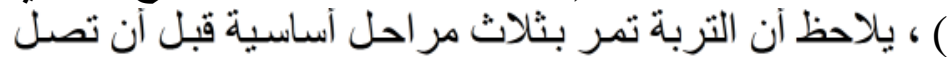

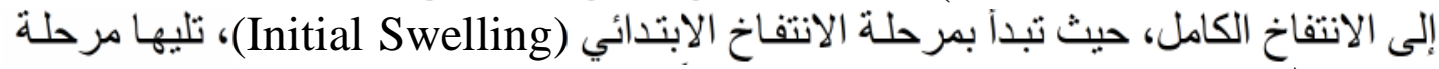
Secondary )

الانتفاخ الرئيسي (Primary Swelling)

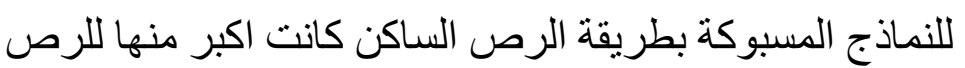

.[1] (Swelling

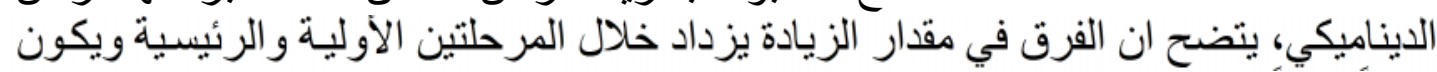

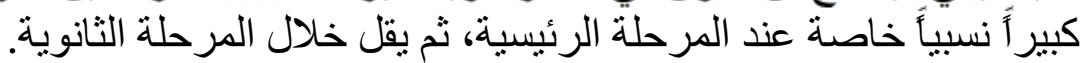

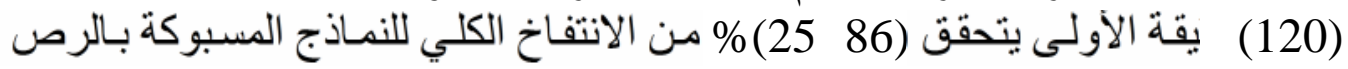

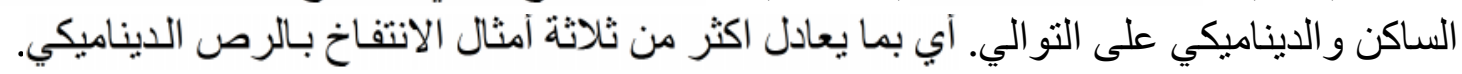

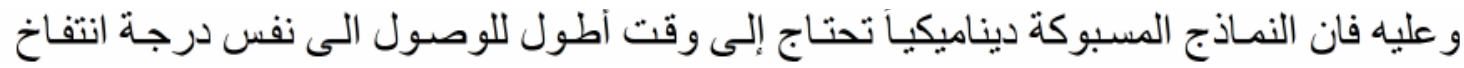

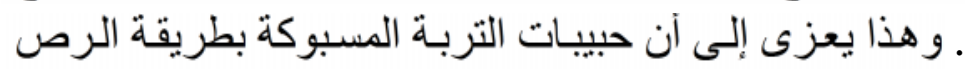

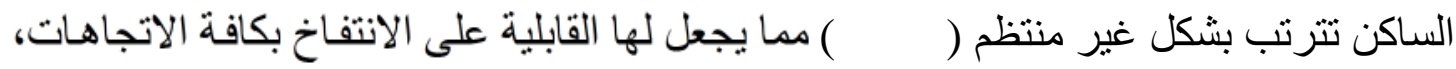

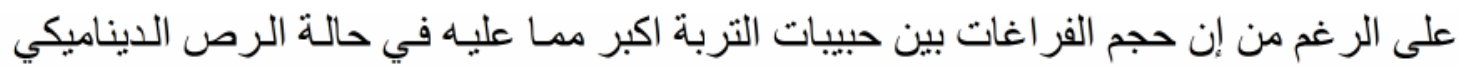

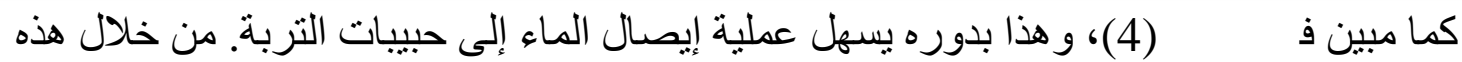

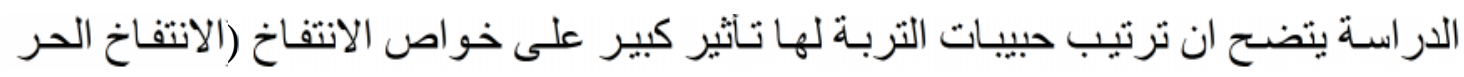

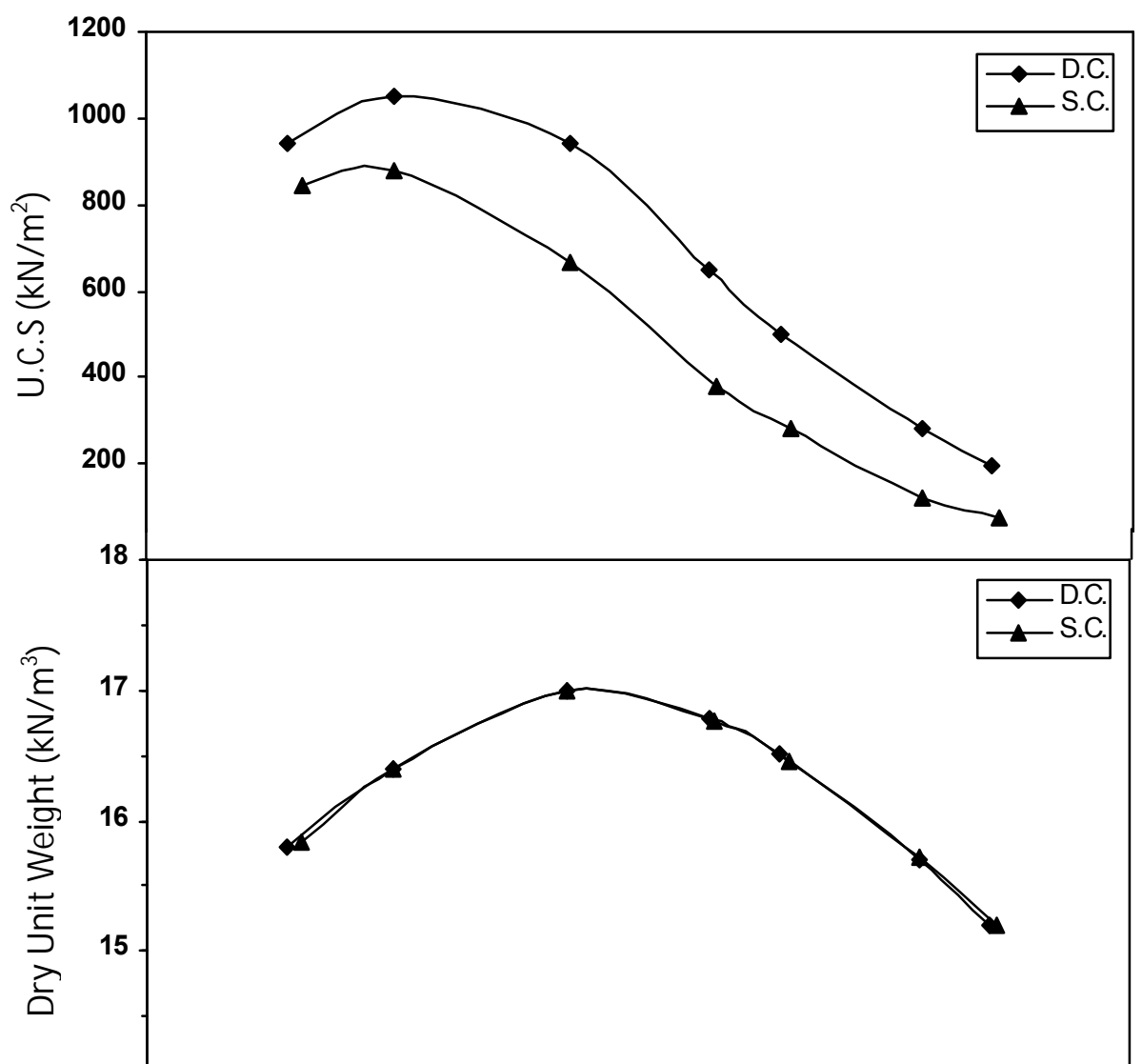


(7) تأثثر طريقة الرص على مقاومة الانضغاط غير

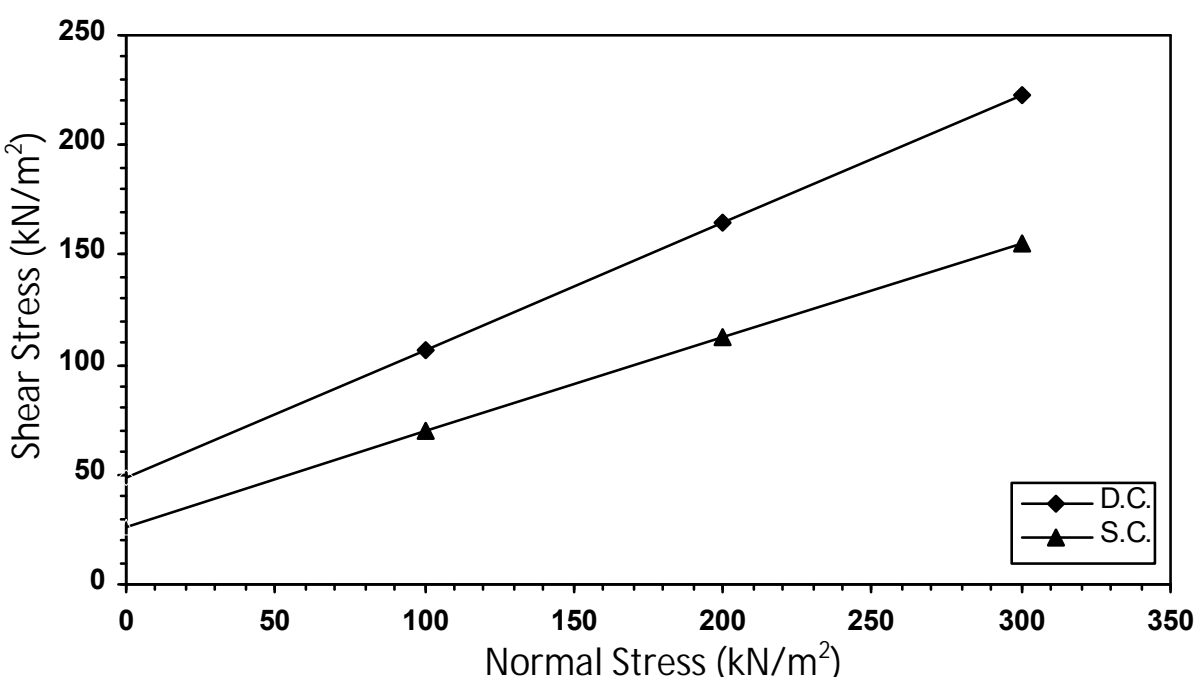

(8) تأثير طريقة الرص على مغلف الفشل ومعاملات قص التربة 


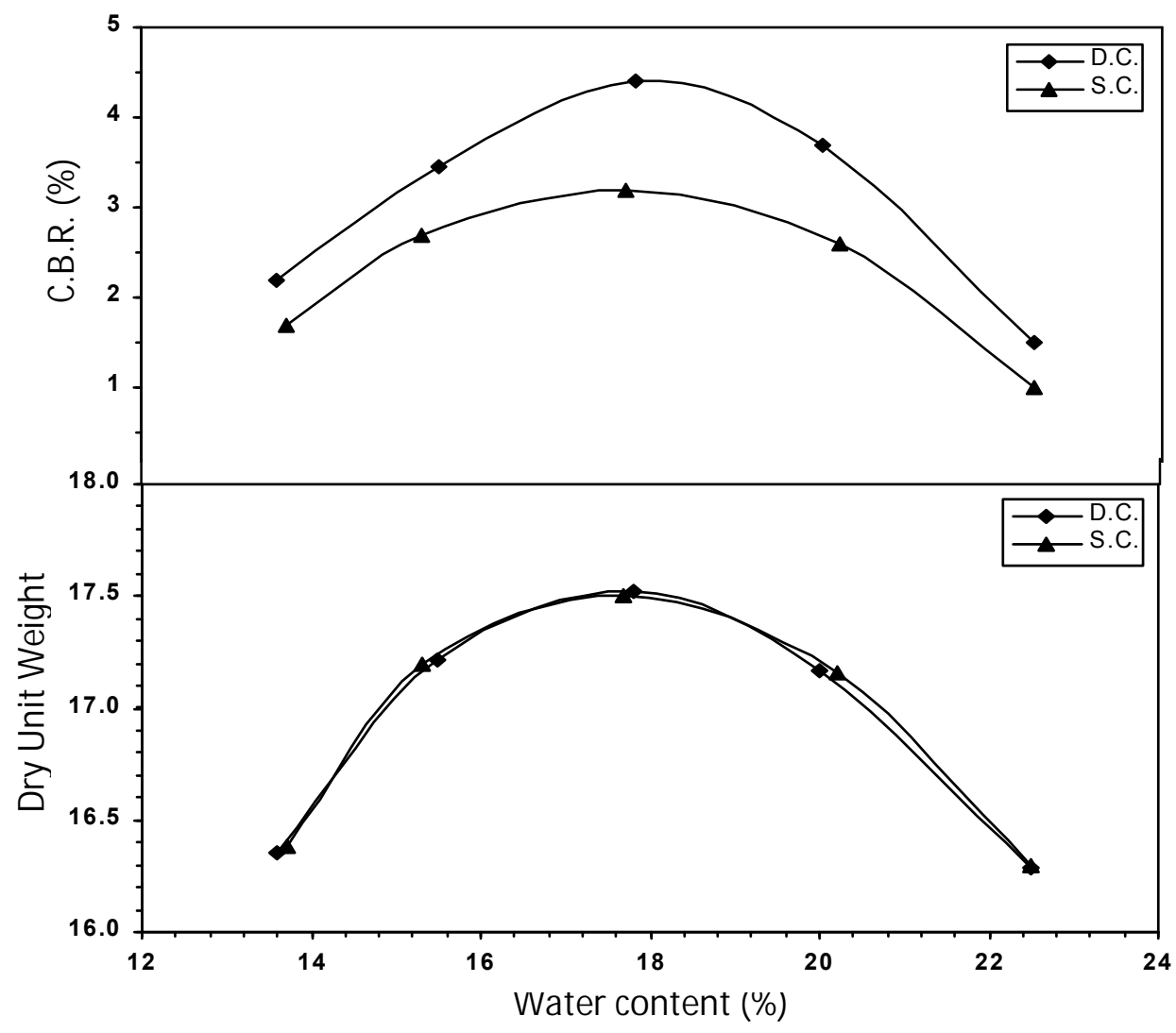


(9) تأثثر طريقة الرص على نسبة التحمل الكاليفورني للتربة

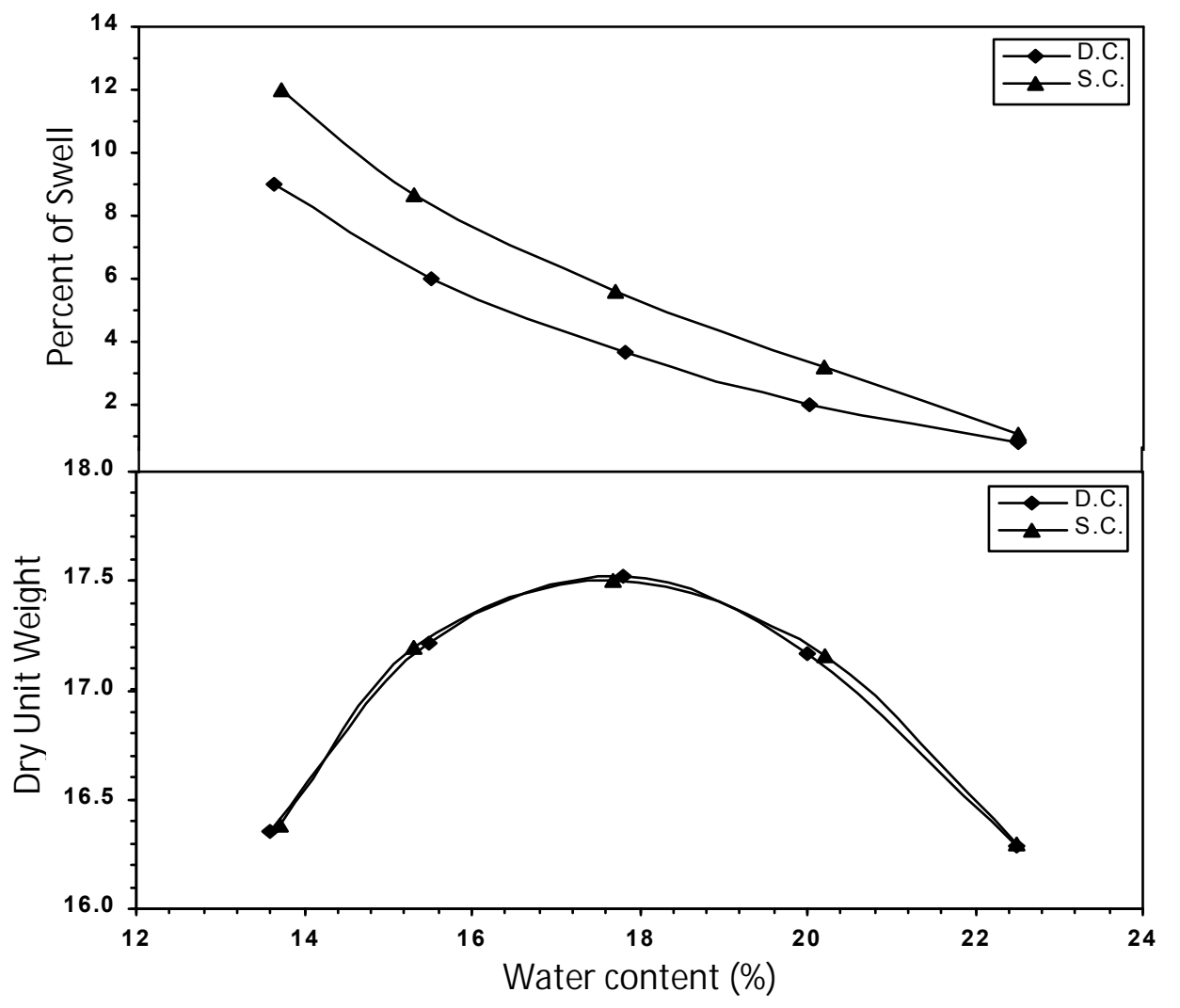


(10) تأثير طريقة الرص على 


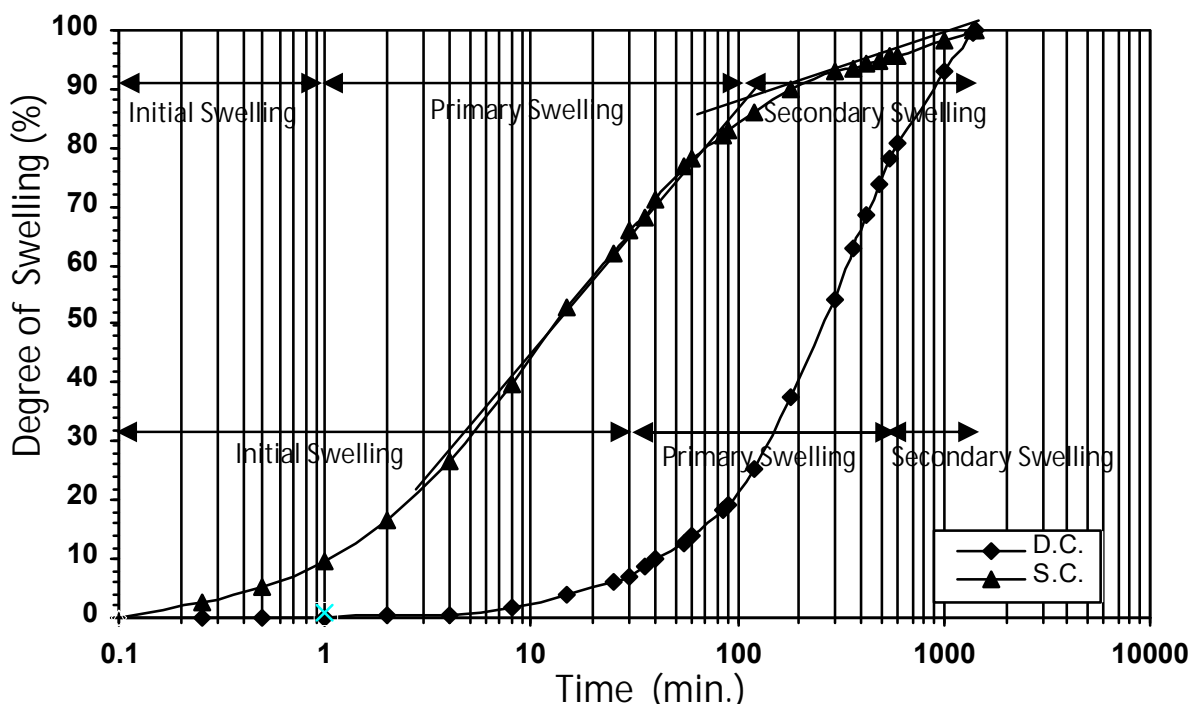

(11) تأثثير طريقة الرص على

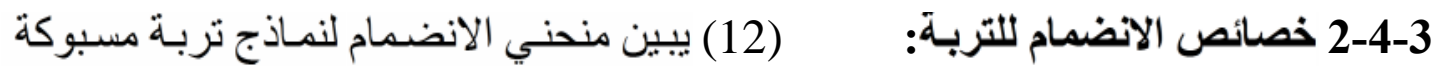

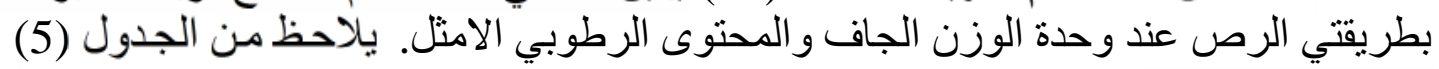

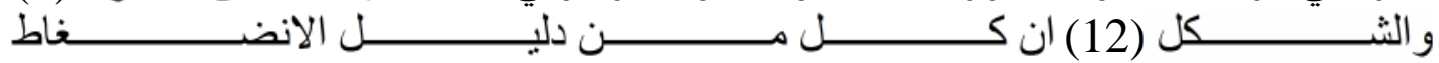

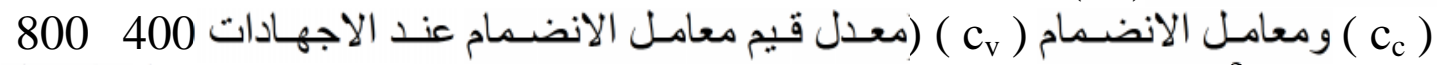
كيلونيوتن / أ2 )

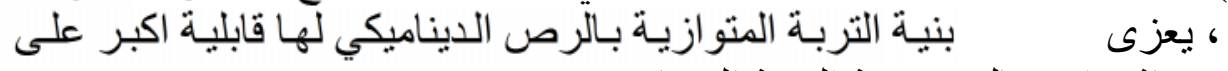

الانضغاط تحت تاثير الاحمال من بنية التربة المتعامدة.

(5) تأثثر طريقة الرص على خصائص

\begin{tabular}{|c|c|c|c|c|c|}
\hline $\begin{array}{l}\mathrm{K} \times 10^{-9} \\
(\mathrm{~cm} / \mathrm{sec})\end{array}$ & $\begin{array}{l}\mathrm{c}_{\mathrm{v}} \times 10^{-2} \\
\left(\mathrm{~cm}^{2} / \mathrm{sec}\right. \\
)\end{array}$ & $c_{\mathrm{s}}$ & $c_{c}$ & $e_{0}$ & طريقة الرص الديناميكي \\
\hline 1.06 & 0.8 & 0.024 & 0.115 & 0.645 & \\
\hline 9.3 & 0.23 & 0.031 & 0.08 & 0.644 & \\
\hline
\end{tabular}




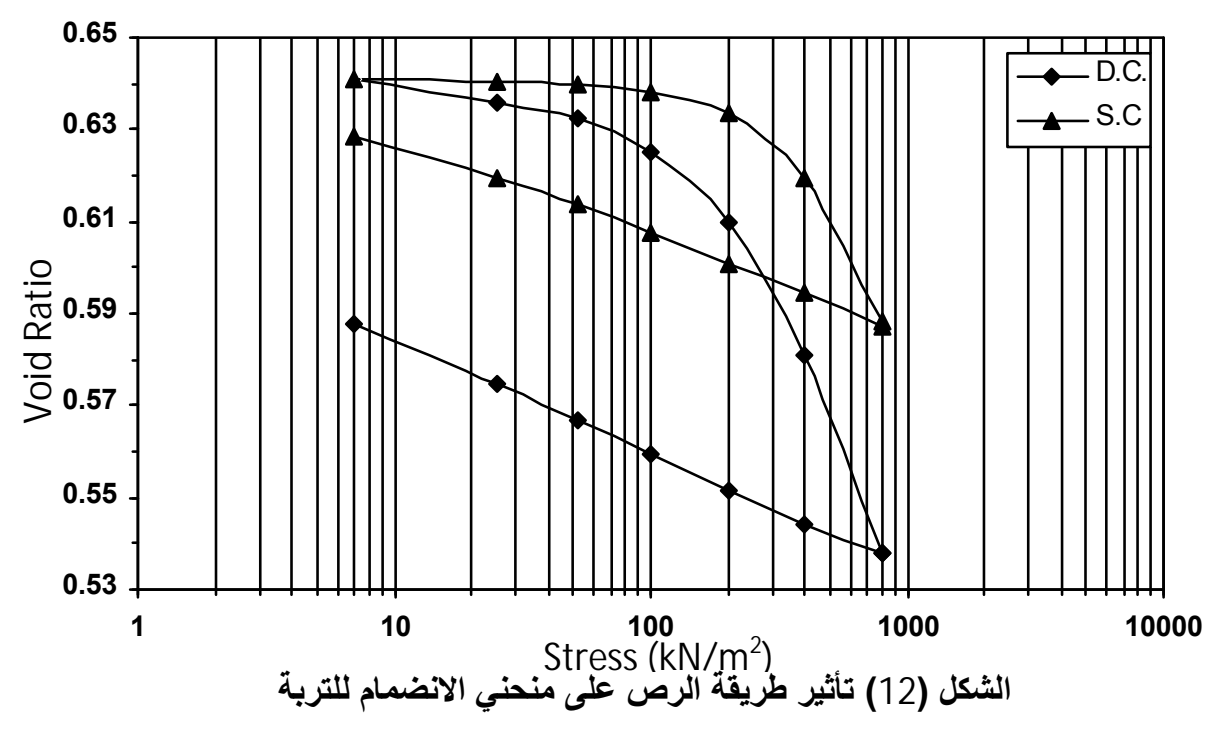

5-3 تأثير طريقة الرص على الخواص الهيدروليكية للتربة:

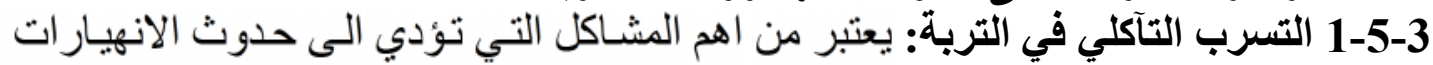

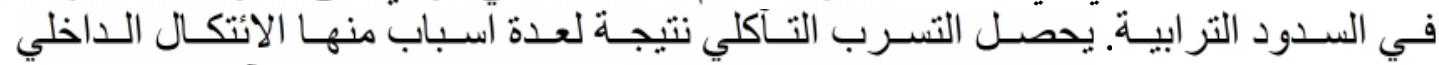
(Internal Erosion)

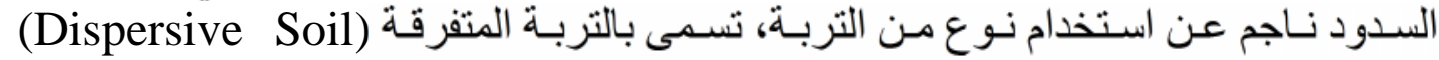

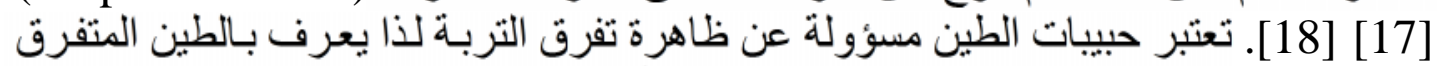
(18ispersive Clay) در اسة تأثير طريقة الرص على التآكل الداخلي للتربة من خلال اجر اء الفحوصات الاتية:

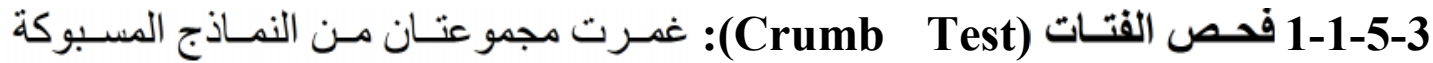

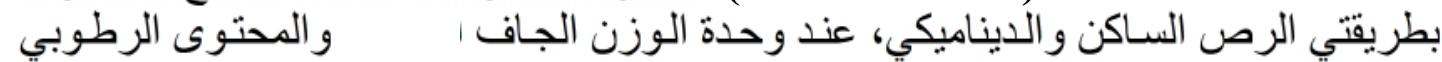

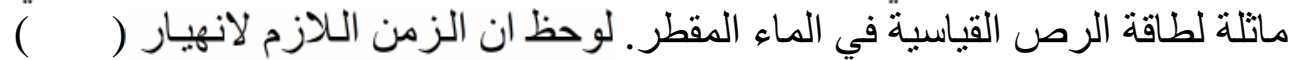

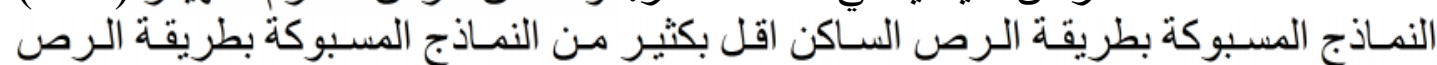

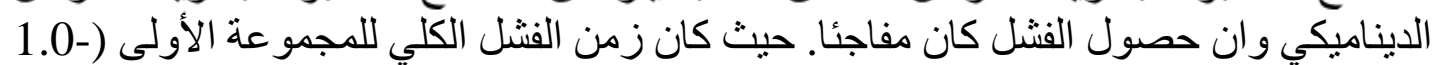

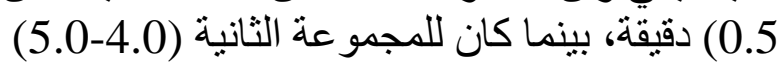

2-1-5-3 فحص الركود (Slackening Test): تم إجر اء الفحص حسب الطريقة المقترحة المهن

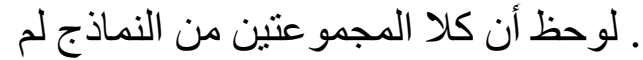

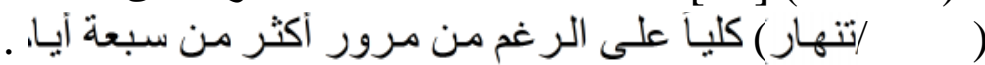

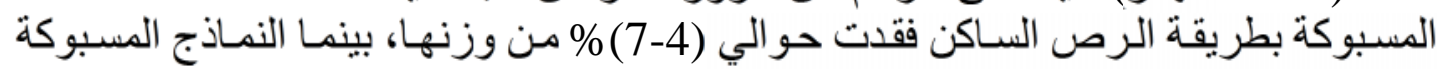
بالطريقة الديناميكية فقدت حو الي (3-5)\% من وزنها.

3-1-5-3 فحص الثقب (Pinhole Test): تم في هذا الفحص استخدام جهاز (19inhole)

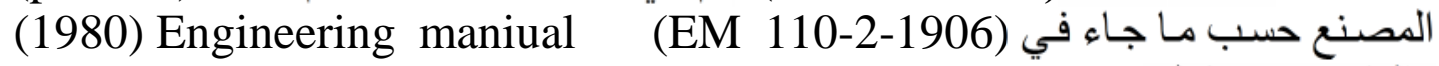
و المقترح من قبل (U.S. Army Engineers Water Ways Experiments Station) 


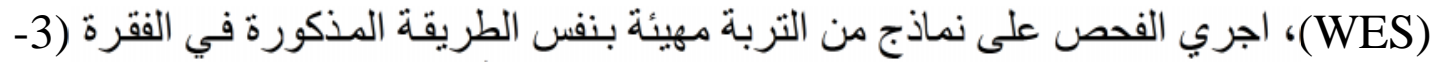

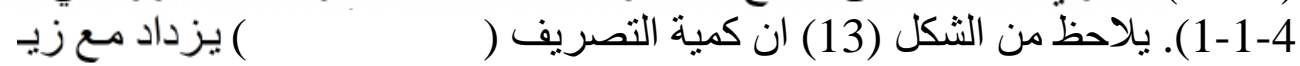

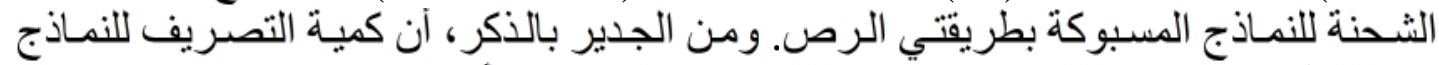

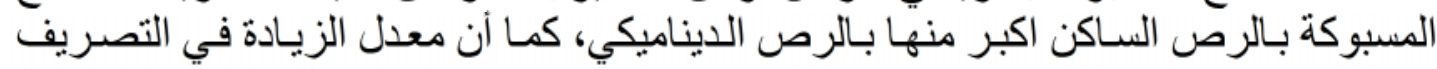

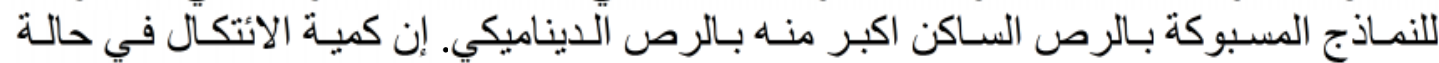

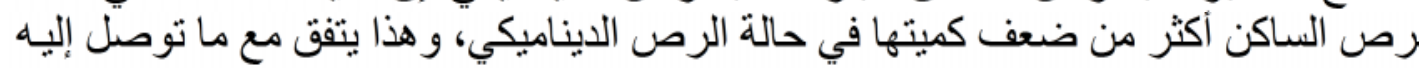

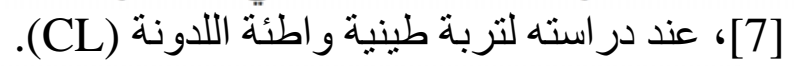

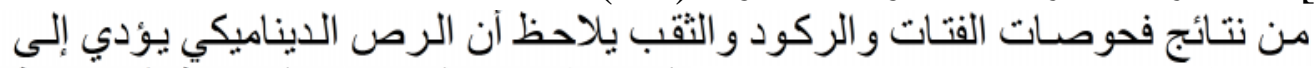

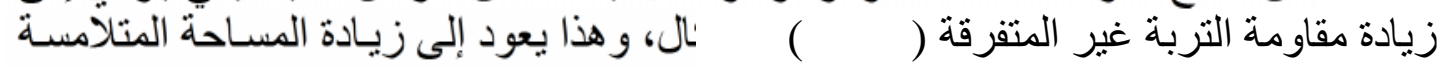

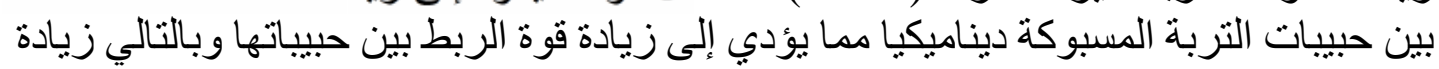

2-5-3 تأثير طريقة الرص على اجهادات مص التربة:

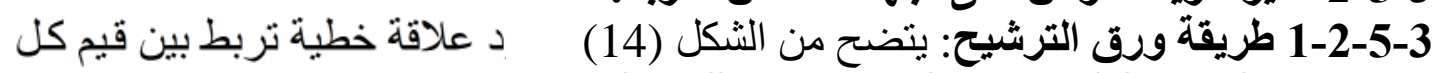

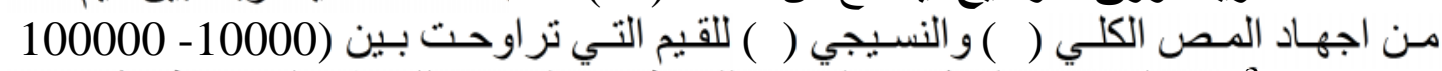

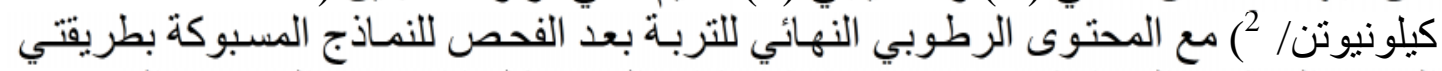

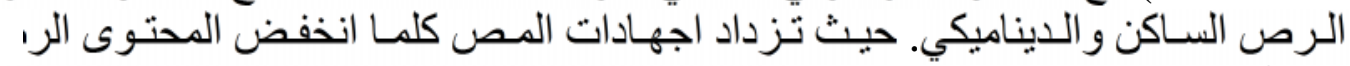

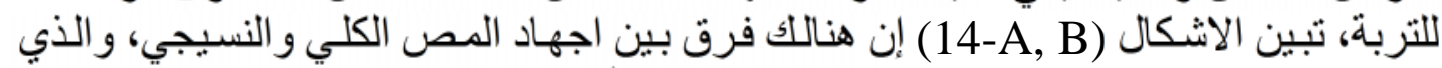

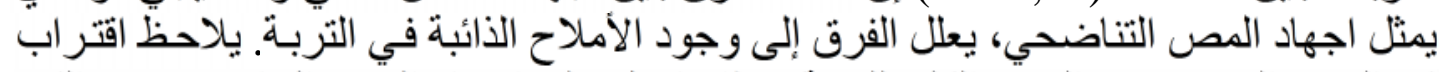

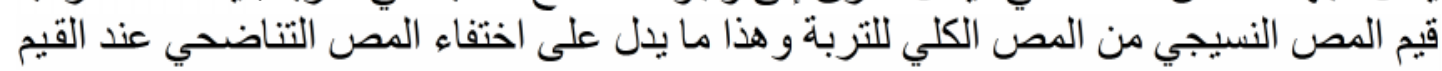
العالية من اجهادات المص عند الخفاض المحتوى الرطوبي للتنربة. $\alpha$

عند در استها لتربة متداعية خلطت بنسب مختلفة من الترب الطينية.

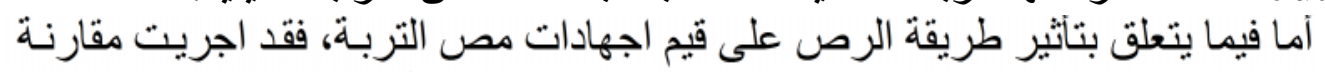

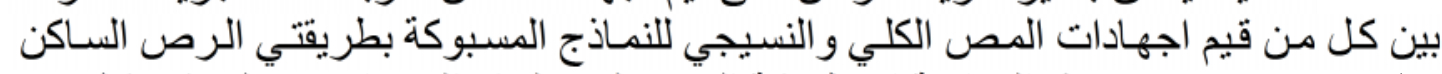

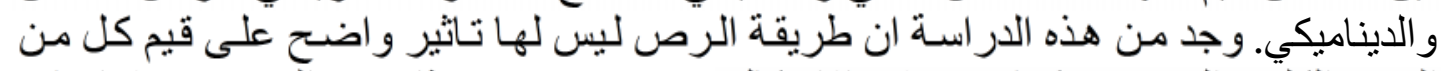

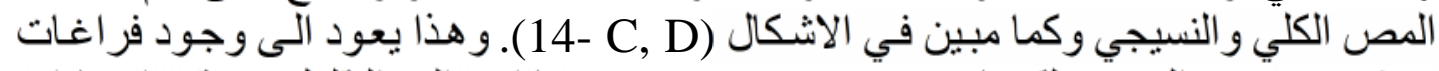

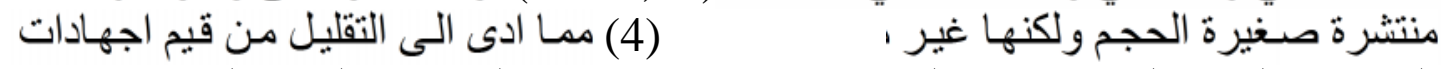
المص في الرص الديناميكي وجعلها مساوية تقريبا لاجهادات المص في الرص الرص الساكن. 


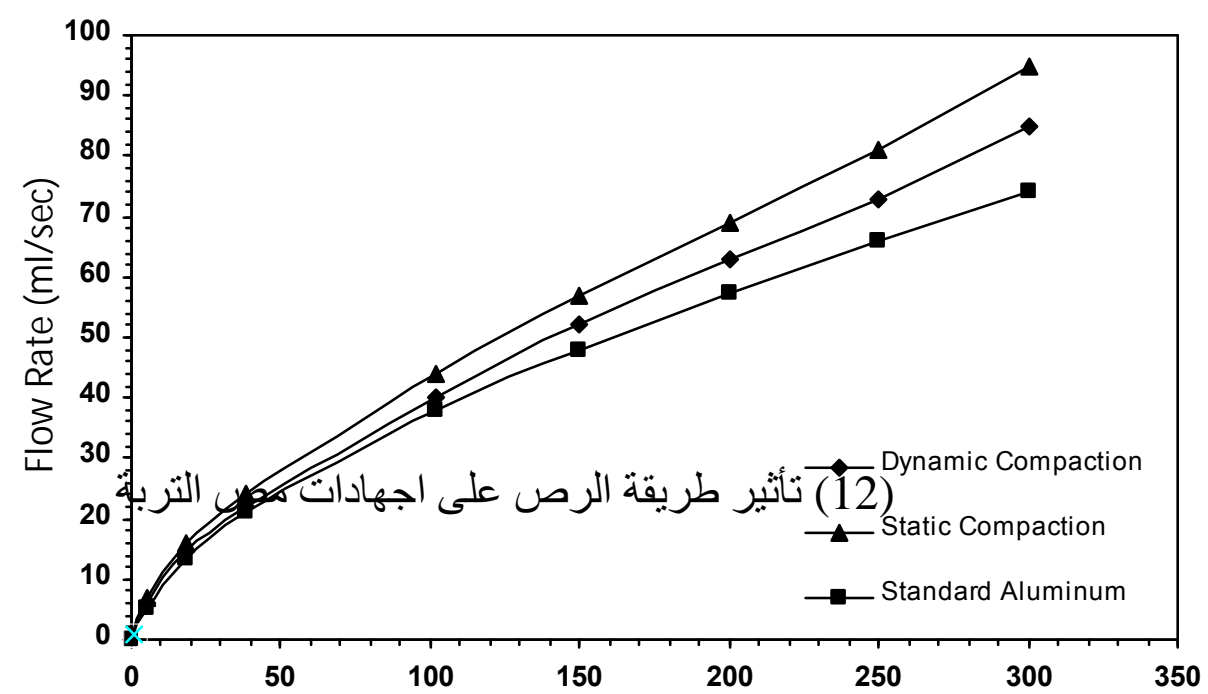

Water Head (cm)

الثكل (13) تأثير طريقة الرص على التسرب ألتآكلي للتربة
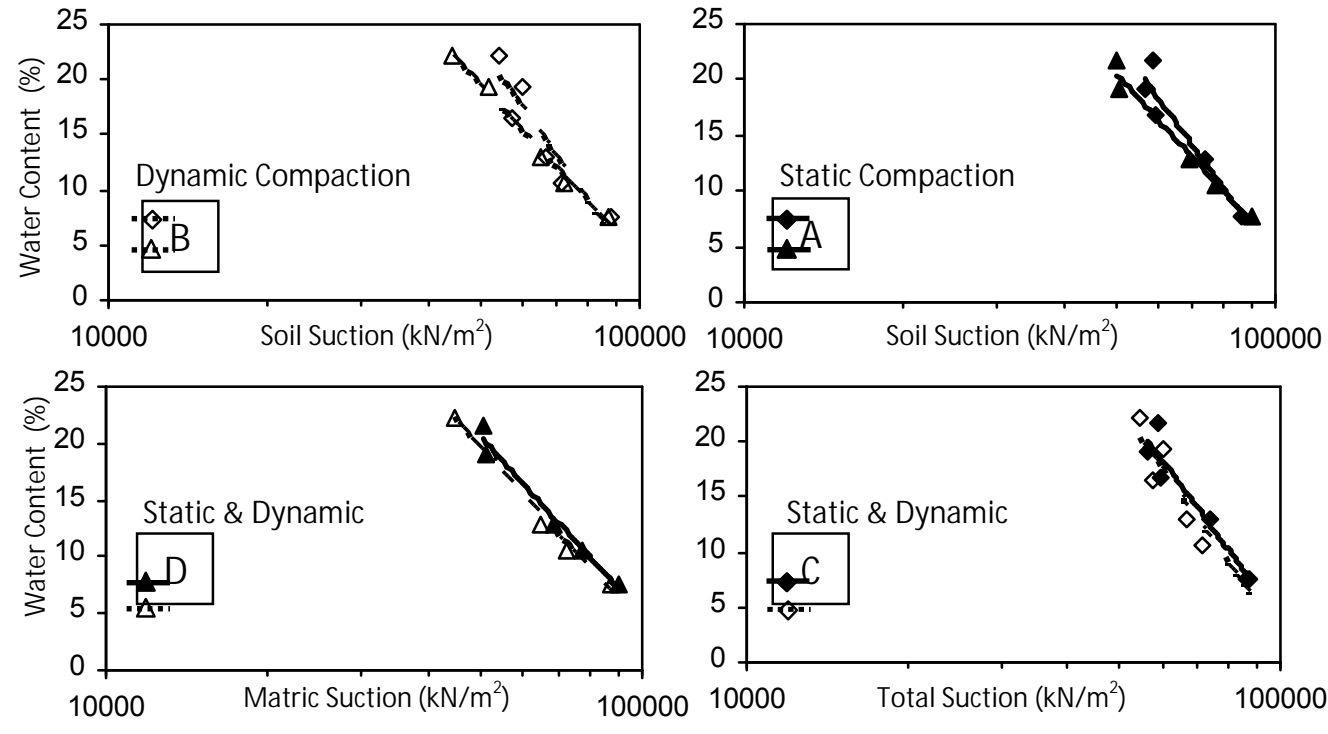

الثكل (14) تأثثر طريقة الرص على اجهاد المص الكلي والنسيجي للتربة 


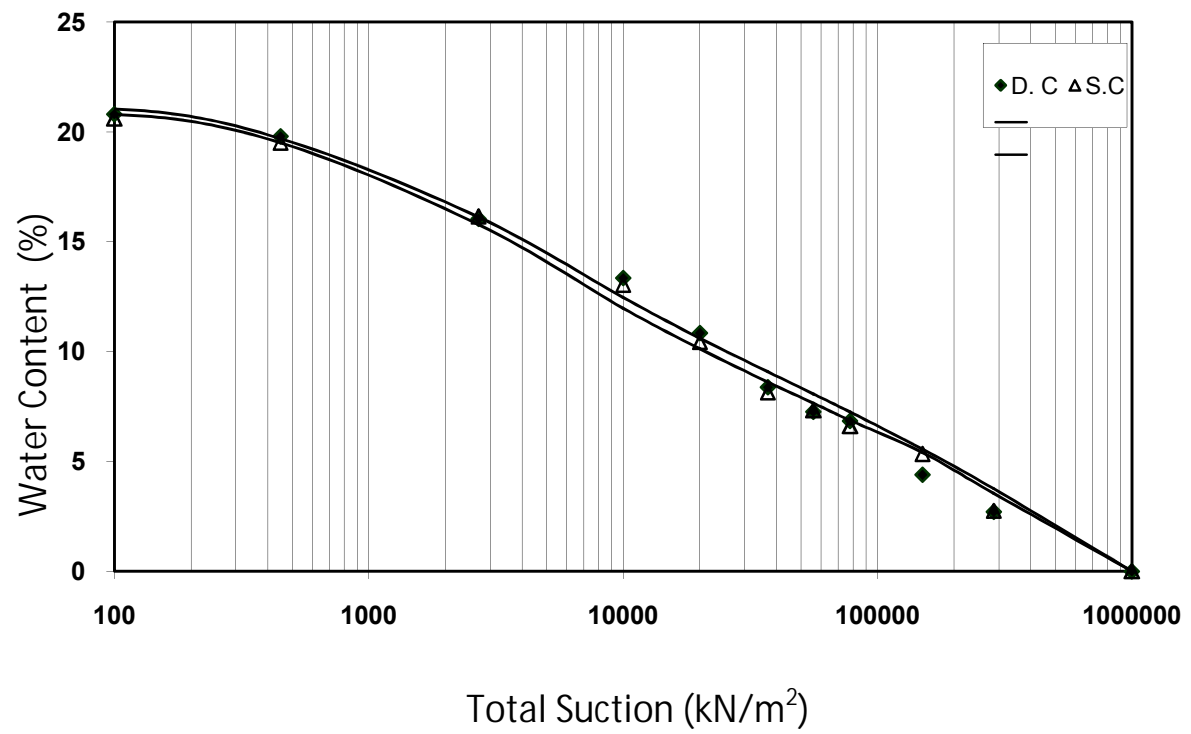

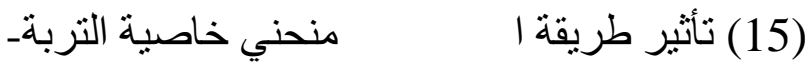




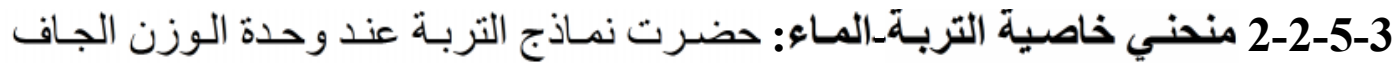

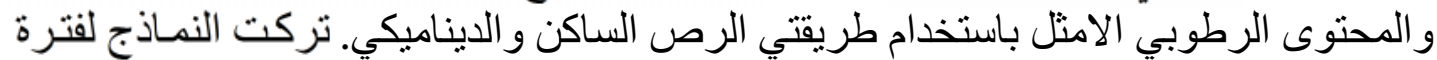

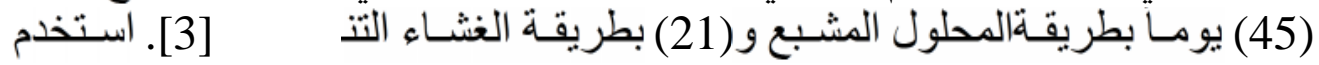

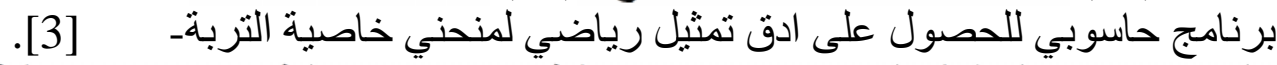

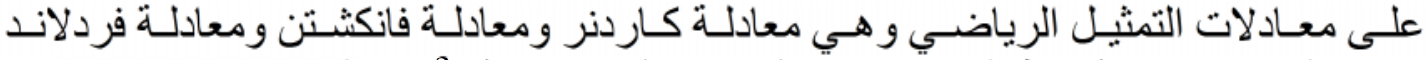

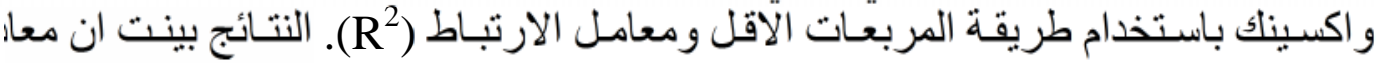

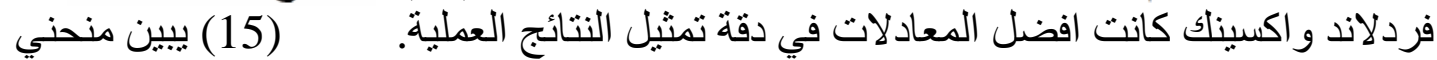

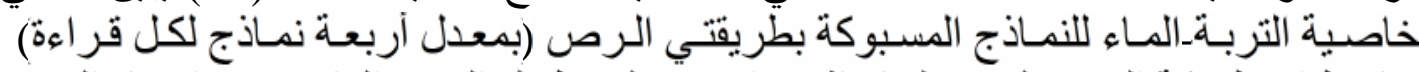

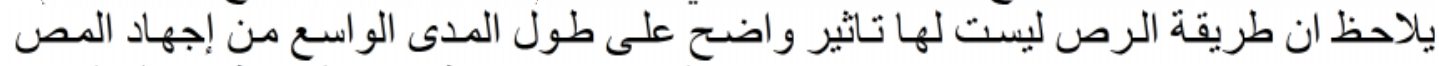

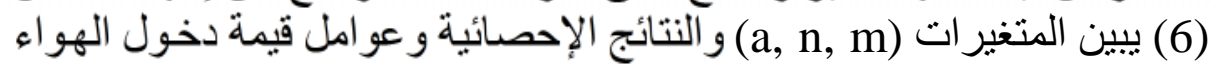

وعو امل الحالة المتبقية.

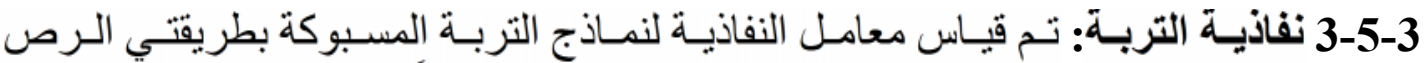

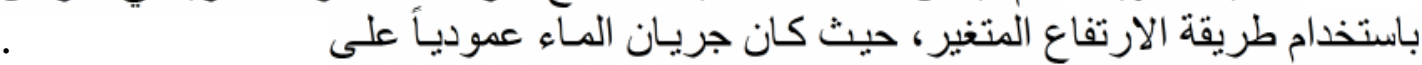
بطريقة الرص السـاكن اعلى منسه بطريقة

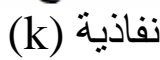

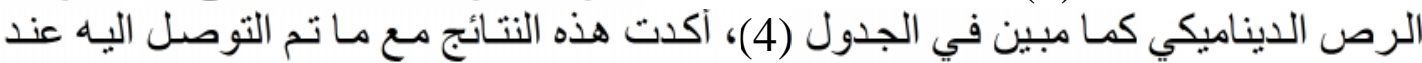

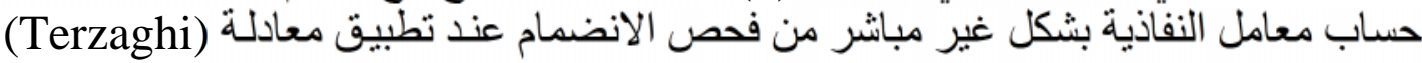

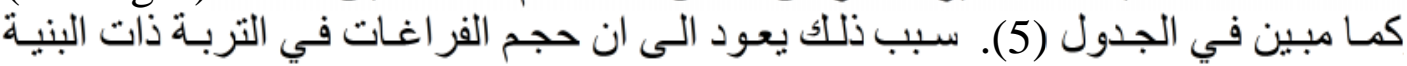

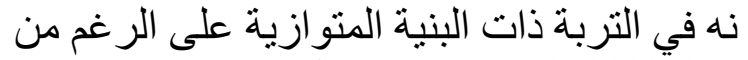

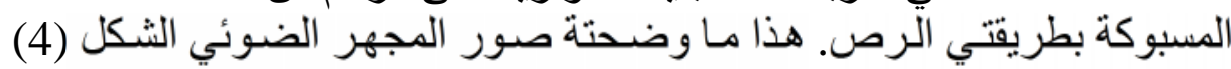
.[20] [4]

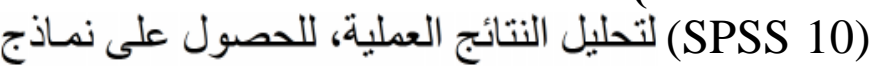

6-3 التحليل الإحصائي (Statistical Analysis):

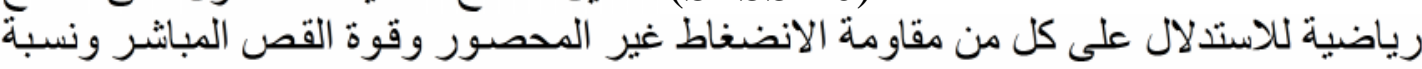

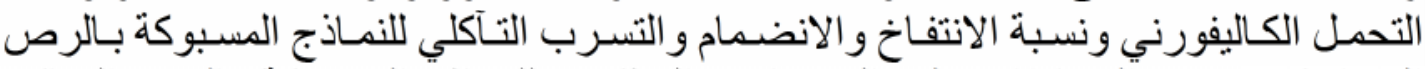

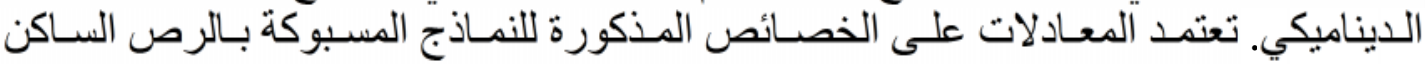 $\left(\mathrm{w}_{\mathrm{o}} \%\right)$
(H m)
(Gs)

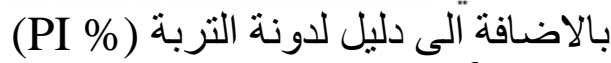 الاولية (V)

(D m)

و عند استخدام الانحدار اللاخطي (Non Linear Regression) على تلك الك البيانات

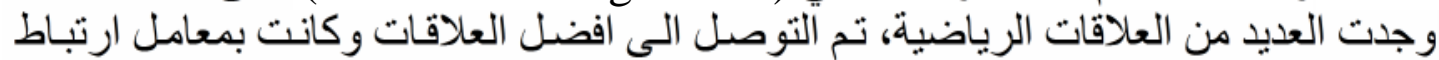

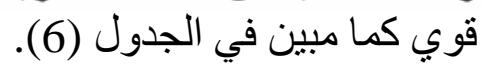

(6) تاثير طريقة الرص على عناصر وعو امل تمثيل منحني خاصية التربةـ

\begin{tabular}{|c|c|c|c|c|c|c|c|c|c|}
\hline \multicolumn{2}{|c|}{ المتبقية } & \multicolumn{2}{|c|}{ دخول الهو قيمة } & \multicolumn{2}{|c|}{ الإحصائية } & & & & \multirow[t]{2}{*}{ طريقة } \\
\hline$\psi \mathrm{r}$ & $\Theta \mathrm{r}$ & $\psi \mathrm{a}$ & $\Theta a$ & $\mathrm{R}^{2}$ & SSR & $\mathrm{m}$ & $\mathrm{n}$ & $\mathrm{a}$ & \\
\hline $\begin{array}{c}3500 \\
0\end{array}$ & 8.7 & 520 & 20.7 & $\begin{array}{c}0.99 \\
6\end{array}$ & $\begin{array}{l}2.45 \\
6\end{array}$ & 0.693 & $\begin{array}{c}0.95 \\
0\end{array}$ & 1500 & \\
\hline $\begin{array}{c}3000 \\
0\end{array}$ & 9.5 & 450 & 20.8 & $\begin{array}{c}0.99 \\
4\end{array}$ & $\begin{array}{l}4.01 \\
4\end{array}$ & 0.700 & $\begin{array}{c}0.90 \\
0\end{array}$ & 1500 & الدينامي \\
\hline
\end{tabular}


(7) نتائج التحليل الاحصائي لبعض الخصائص الهندية للتربة المسبوكة بطريقتي

\begin{tabular}{|c|c|c|}
\hline Test & Regression Model & $\mathrm{R}^{2}$ \\
\hline UCS & $\underset{0.8466}{\mathrm{q}_{\mathrm{u} \mathrm{dy}}}=19.2922\left(\mathrm{q}_{\mathrm{u} \text { st. }}\right)^{0.907} \mathrm{x}\left(\mathrm{PI} / \mathrm{w}_{\mathrm{o}}\right)^{-1.1275} \mathrm{x}\left(\gamma_{\mathrm{d}} / \mathrm{Gs} \gamma_{\mathrm{w}}\right)^{-}$ & $\begin{array}{c}0.999 \\
9\end{array}$ \\
\hline $\begin{array}{l}\text { Direct } \\
\text { Shear }\end{array}$ & $\tau_{\text {dy. }}=\tau_{\text {st. }}{ }^{0.948}+\left(\mathrm{PI} / \mathrm{w}_{\mathrm{o}}\right)^{4.898}-\left(\gamma_{\mathrm{d}} / \mathrm{Gs} \gamma_{\mathrm{w}}\right)^{1.675}$ & $\begin{array}{c}0.999 \\
9\end{array}$ \\
\hline CBR & $\begin{array}{l}\mathrm{CBR}_{\mathrm{dy}}=12.0809\left(\mathrm{CBR}_{\mathrm{st}}\right)^{1.0645} \times\left(\mathrm{PI} / \mathrm{w}_{\mathrm{o}}\right)^{-0.3789} \mathrm{x}\left(\gamma_{\mathrm{d}} /\right. \\
\left.\mathrm{Gs}_{\mathrm{w}}\right)^{-1.128}\end{array}$ & $\begin{array}{c}0.998 \\
4\end{array}$ \\
\hline $\begin{array}{l}\text { Swelli } \\
\text { ng }\end{array}$ & $\begin{array}{l}\text { Swell }{ }_{\mathrm{dy}}=0.20539\left(\text { swell }_{\text {st. }}\right)^{0.6905} \mathrm{x}\left(\mathrm{PI} / \mathrm{w}_{\mathrm{o}}\right)^{1.565} \mathrm{x}\left(\gamma_{\mathrm{d}} /\right. \\
\left.\mathrm{Gs} \gamma_{\mathrm{w}}\right)^{0.552}\end{array}$ & $\begin{array}{c}0.999 \\
9\end{array}$ \\
\hline $\begin{array}{l}\text { Consol } \\
\text { i- } \\
\text { dation }\end{array}$ & $\mathrm{c}_{\mathrm{c} \mathrm{dy}}=0.01\left(\mathrm{c}_{\mathrm{c} \mathrm{st}}\right)^{0.714}+\left(\mathrm{PI} / \mathrm{w}_{\mathrm{o}}\right)^{0.259}-\left(\gamma_{\mathrm{d}} / \mathrm{Gs} \gamma_{\mathrm{w}}\right)^{0.0642}$ & $\begin{array}{c}0.984 \\
2\end{array}$ \\
\hline $\begin{array}{l}\text { Pinhol } \\
\text { e Test }\end{array}$ & $\begin{array}{l}\mathrm{Q}_{\mathrm{dy}}=\left(\mathrm{Q}_{\mathrm{st}}\right)^{0.9776}+(\mathrm{H} / \mathrm{D})^{-0.108}+\left(\mathrm{PI} / \mathrm{w}_{\mathrm{o}}\right)^{6.745}-\left(\gamma_{\mathrm{d}} / \mathrm{Gs}\right. \\
\left.\gamma_{\mathrm{w}}\right)^{0.8044}\end{array}$ & $\begin{array}{c}0.994 \\
0\end{array}$ \\
\hline
\end{tabular}

$$
4 \text { - 2 - الاستنتاجات }
$$

من خلال هذه الدر اسة تم التوصل الى الاستنتاجات التالية:

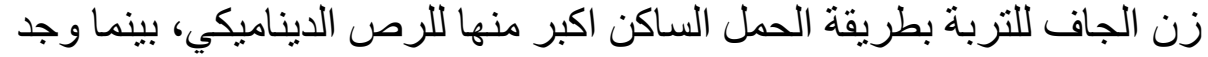

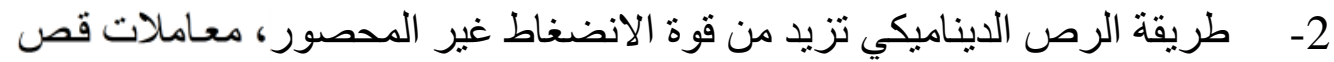

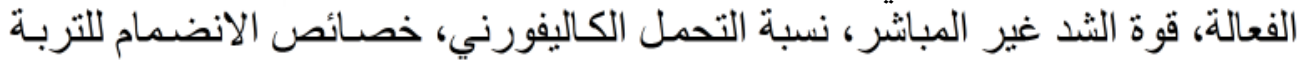

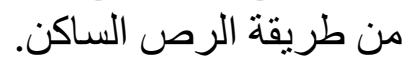
3- طريقة الرص السـاكن تجعل التربـة ذات نفاذيـة وخصـائص انتفاخيـة اكبر من طريقة

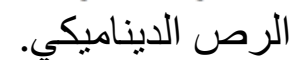

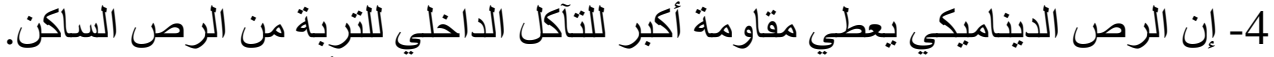

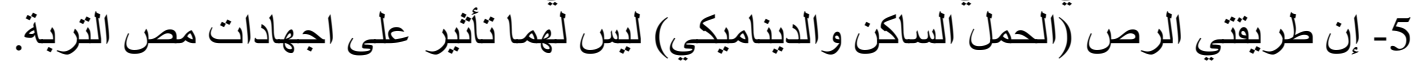

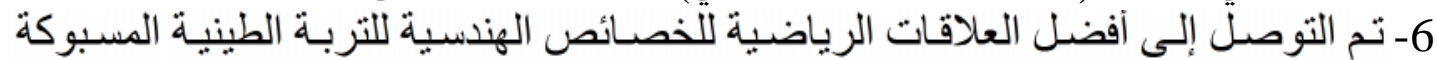
الرص (الحمل الساكن و الديناميكي).

1. AL-Barwary, M., "Effect of Wetting and Drying Cycles on Swelling Properties of Soil under Different Loading in Summel City" M.Sc. thesis, University of Mosul, Iraq, 2006. 
2. Al-Juari, K., "The Effect of Clay Percentage on Volume Change of Collapsible Soil In Mosul City" M.Sc. thesis, University of Mosul, Iraq, 2005.

3. Al-Taie, L., "Correlation between Suction and some engineering properties of lime stabilized clayey Soil from Mosul City" M.Sc. thesis, University of Mosul, Iraq, 2005.

4. Arora, K. R., "Introductory Soil Engineering", Standard publishers Distributors, Delhi, 1988.

5. Attom, M.F., Abu-Zreig, M.M. and Obaidar, M.T. "Changes in Clay Swelling and Shear Strength Properties with Different Sample Preparation Techniques" Geotechnical testing Journal, GTJODJ, Vol. 24, No.2, pp.157-163. 2001.

6. Das, B. M., "Introduction to Soil Mechanics", Iowa state university press, India, 1989.

7. Fatah, A.A., "Study of Earth Dams Failure by Piping" M.Sc. thesis, University of Salahaddin, Iraq, 1990.

8. Khattab, S.A.A., "Eude Multi-echelles d'un Sol Plastique Traitè à la Chaux", Thèse de Doctorat, Universitè d 'Orleans, France. 2002.

9. Lambe, T.W., "Soil Testing for Engineers", Wiley Eastern - Limited, India, 1984.

10. Lambe , T.W. , "The Engineering Behavior of Compacted Clay" Journal, Soil Mechanics and foundation division, American Society of Civil Engineering, Vol. 84 , No. SM2 May, 1958.

11. Lambe T.W., "The structure of compacted clay", Journal, Soil Mechanics and foundation division, American Society of Civil Engineering, Vol. 84, No. SM2 May, 1958.

12. Leong, E.C., He, L. and Rahardjo, H.,"Factors Affecting Filter Paper Method for Total and Matric Suction Measurements", Geotehnical Testing Journal, Vol. 25, No. 3, pp. 1-12, 2002.

13. Mitchel, J.K., "Fundamental of Soil Behavior", John Wiley, New York, 1976. 
14. Olsen, E. R. and Mesri, A. M., "Mechanism Controlling Compressibility of Clays", J. S. M. F. Div., Proceeding of The ASCE, Vol.96, No.SM6, 1970.

15. Rahimi, R.; Abbasi, N. And Davarzani, H., "Physical Dispersivity Phenomenon and Its Evaluation Criteria in Cohesion less Soils". $2^{\text {nd }}$ International conference on advances in soft soil engineering and technology, 2-4 July, Putrajava, Malaysia, 2003.

16. Seed, H. B. and Chan, C. K.," Structure and Strength Characteristics of Compaction Clays",Journal of the Soil Mechanics and Foundation Division, Proceeding of the American Society of Civil Engineers, Vol. 85, No. SM 5, pp. 87- 128, October, 1959.

17. Shaikh, A., Ruff, J.F. and Abt, S.R., "Erosion Rate of compacted NAMontmorillonite Soils", J, Geotechnical Engineering. IV., Proc. ASCE, Vol. 114, No. 3, March, PP. 296-305. 1988.

18.Sherard, J.L., Decker, R.S. and Ryker, N.L. "Piping in earth dams of dispersive clay", Proc. ASCE, Specialty Conference on the Performance of earth and earth-supported structures, vol.1, june, pp. 589-626. 1972.

19. Sobhan, K. And Mashnad, M., " Mechanical Stabilization of Cemented Soil- Fly Ash Mixtures with Recycled Plastic Strips", Journal of environmental engineering, Vol. 129, No. 10, October 1, 2003.

20. Todd, D.K., " Ground Water Hydrology ", Toppan Company, Ltd., Tokyo, Japan, PP. 94, 1959. 
